\title{
Laboralización de la función pública. Reflexiones a propósito del debate sobre la aplicación de la acción de tutela de derechos fundamentales a los trabajadores públicos
}

\author{
Turning public employment into employment law. Reflexions \\ around the debate on supplemental application of the proceedings \\ on human rights within the employment relationship to public workers
}

\author{
Karla Varas Marchant \\ Pontificia Universidad Católica de Valparaíso, Chile
}

\section{RESUMEN}

La doctrina clásica administrativista postula que quienes trabajan en la Administración Pública deben estar sometidos a un régimen de derecho público, de carácter estatutario y no contractual, con una regulación en la órbita del derecho administrativo. El trabajo que realizan estas personas, por tanto, no debe quedar entregado a la regulación del régimen jurídico de la relación laboral privada (el derecho del trabajo). El objetivo principal de este artículo será derribar la clásica tesis de separación entre el trabajo desarrollado en el sector público del desarrollado en el sector privado, postulando que, en razón de la vocación de universalidad del derecho del trabajo, el constante crecimiento del aparato administrativo y el consecuente aumento de su personal, dicho régimen jurídico poco a poco ha ido tomando un protagonismo importante. Para demostrar que el sistema de función pública chileno está transitando hacia lo que se ha denominado fenómeno de laboralización de la función pública, analizaremos la problemática derivada de la aplicación de la acción de tutela de derechos fundamentales regulada en el Código del Trabajo a los trabajadores del sector público regidos por la normativa estatutaria. A partir de este análisis, demostraremos que el derecho del trabajo poco a poco ha ido avanzando hacia tierras que le eran ajenas, en aras de la protección del trabajo subordinado.

\section{PALABRAS CLAVE}

Laboralización función pública · tutela laboral · funcionarios públicos · derechos fundamentales. 


\section{ABSTRACT}

The classical administrative theory proposes that those who work in the field of Public Administration must be subject to the regime of public law, statutory and non-contractual, with its regulation located in the orbit of administrative law. The work carried out by public employees, therefore, should not be handed over to the regulation of the legal regime of the private employment relationship under Labour Law. The main objective of this article will be to dismantle the classical theory of separation between the work carried out in the public sector from that carried out in the private sector, asserting that due to the universality of labour law, the constant growth of the administrative apparatus and the consequent increase in its staff, the public law regime has gradually taken on an important role. To demonstrate that the Chilean public administration system is moving towards what has been called the phenomenon of laborization of the public function, we will analyze the problems derived from the application of the action for the protection of fundamental rights regulated in the Labor Code for workers in the public sector governed by statutory regulations. Based on this analysis, we will show that the labor law has been gradually advancing towards unchartered waters for the sake of the protection of subordinate labor.

\section{KEY WORDS}

Public sector labor $\cdot$ labor protection $\cdot$ public officials $\cdot$ fundamental rights.

\section{INTRODUCCIÓN}

En sus orígenes, el derecho del trabajo no tuvo en vista la regulación del trabajo del sector público. Como expresa Supiot, «el derecho del trabajo es, esencialmente, el derecho del trabajo remunerado y no rige, en principio, el trabajo independiente, el trabajo dentro de la Administración pública o el trabajo a título gratuito».

El régimen legal típico de la función pública no está en la órbita del derecho del trabajo, sino en la del derecho administrativo; la regulación del empleo público se define por leyes y reglamentos. Por el contrario, el régimen laboral privado, si bien contempla un estatuto protector, da una amplia cabida a la contractualidad, la que actúa en todo su esplendor en el ámbito de las relaciones colectivas de trabajo. Sobre esta base se ha marcado una tajante separación entre el derecho del trabajo y el derecho de la función pública, que se ha justificado, entre otros motivos, en la necesidad de que el Estado se provea de cuerpos especializados de funcionarios que atiendan las necesidades de la gestión pública, sin ser capturados por grupos de interés o presión, especialmente políticos. ${ }^{2}$

' Supiot, Alain, Derecho del Trabajo (Buenos Aires, Editorial Heliasta, 2008), p. Io.

2 En ese sentido, Rajevic, Enrique, La precarización del empleo público en Chile y el mito de la carrera funcionaria, en Quinto Encuentro Anual de la Sociedad Chilena de Políticas Públicas (Santiago, enero de 20I4), p. I. 
Con el tiempo, la tajante separación de la regulación del trabajo en el sector privado del trabajo en el sector público se ha ido relativizando, especialmente porque instituciones clave del derecho del trabajo - tutela de derechos fundamentales, derechos colectivos, entre otras-, han traspasado las fronteras del trabajador asalariado del mundo privado, en razón de la atracción que ejercen sobre otras formas de trabajo humano subordinado, como es el realizado en el sector público. ${ }^{3}$

La expansión que ha tenido el derecho del trabajo al ámbito de la función pública ha sido denominada fenómeno de laboralización de la función pública. ${ }^{4}$ Se trata, como su nombre lo indica, de la aplicación de instituciones propias del derecho del trabajo al ámbito de la función pública. Ahora, esta laboralización puede ser de carácter parcial (laboralización débil) o total (laboralización fuerte).

En este contexto, el objetivo principal de este artículo será derribar la clásica tesis de separación entre el trabajo desarrollado en el sector público del desarrollado en el sector privado, postulando que, debido a la vocación de universalidad del derecho del trabajo, el constante crecimiento del aparato administrativo y el consecuente aumento de su personal, dicho régimen jurídico poco a poco ha ido tomando un protagonismo importante.

Para demostrar que el sistema de función pública chileno ha transitado hacia lo que se ha denominado fenómeno de laboralización de la función pública, analizaremos la problemática derivada de la aplicación de la acción de tutela de derechos fundamentales regulada en el Código del Trabajo, a los trabajadores del sector público regidos por la normativa estatutaria. A partir de este análisis, demostraremos que el derecho del trabajo poco a poco ha ido avanzando hacia tierras que le eran ajenas, en aras de la protección del trabajo subordinado.

3 Supiot, Alain, Derecho del Trabajo, cit. (n. i), p. Io.

${ }_{4}$ Otra forma de referirse a este fenómeno es a través de la idea de la «huida del derecho administrativo", abandonándose elementos o concepciones clásicas de la función pública por instituciones propias del derecho del trabajo. Por ejemplo, al introducirse al ámbito del empleo público mecanismos de participación de los trabajadores en la determinación de sus condiciones de trabajo, como el derecho de negociación colectiva, se abandona el clásico postulado de que las condiciones laborales en la Administración Pública son fijadas de forma unilateral por la ley. Marín VAlLejo, Urbano, Estatuto Administrativo: ¿Régimen en retirada en la Administración Pública chilena?, en Pantoja Bauzá, Rolando (coord.), La Administración del Estado de Chile. Decenio 1990-200o (Santiago, Editorial Jurídica Cono Sur, 2000), p. 203. 


\section{LA CONCEPCIÓN CLÁSICA: LA REGULACIÓN ESTATUTARIA DEL EMPLEO PÚBLICO}

Para que el Estado pueda realizar el cometido que por mandato constitucional está llamado a realizar — promover el bien común—, 5 debe dotarse de un fuerte aparato institucional que sea capaz de satisfacer las necesidades que demanda la sociedad. Detrás de ese gran aparato institucional hay un sin número de personas que llevan a la práctica el cometido estatal de promover el bien común. Tradicionalmente, esas personas han sido denominadas funcionarios o empleados públicos, con el objeto de marcar una clara distinción respecto de quienes prestan servicios en el sector privado; con ello se les niega la calidad de trabajadores. ${ }^{6}$

La especial naturaleza del acreedor de los frutos del trabajo (el Estado), el fin perseguido a través de los servicios públicos (la satisfacción de necesidades generales), sus características especiales (continuidad y regularidad) y la supremacía de la Administración Pública con relación al funcionario, han sido algunos de los elementos que justificaron la necesidad de que el trabajo en el sector público esté sometido a una regulación especial. El núcleo central de este régimen especial radica en que las condiciones laborales son fijadas unilateralmente por el poder público a través de leyes y reglamentos. Así, es un estatuto público el que determina los derechos, deberes y responsabilidades de los funcionarios. De ahí que se hable de una relación estatutaria no contractual.

De esta forma, antes del ingreso a la Administración, los derechos y deberes de quienes prestarán servicios están previamente definidos de forma objetiva e impersonal, los que no pueden ser alterados para ningún funcionario en específico, ni siquiera a través de procesos de negociación

s Ello, en virtud del mandato contenido en el artículo I incisos tercero y cuarto de la Constitución Política que dispone: "El Estado está al servicio de la persona humana y su finalidad es promover el bien común, para lo cual debe contribuir a crear las condiciones sociales que permitan a todos y a cada uno de los integrantes de la comunidad nacional su mayor realización espiritual y material posible, con pleno respeto a los derechos y garantías que esta Constitución establece.

"Es deber del Estado resguardar la seguridad nacional, dar protección a la población y la familia, propender al fortalecimiento de ésta, promover la integración armónica de todos los sectores de la Nación y asegurar el derecho de las personas a participar con igualdad de oportunidades en la vida nacional».

${ }^{6}$ Como expresa Binder, «la propia denominación de funcionario hace alusión a que no se trata de un trabajador normal, sino que encarna una función pública y es, en consecuencia, parte de la organización del Estado (teoría del órgano)». BINDER, Jaime, La laboralización de la función pública y la nueva gestión pública, en Boletín Oficial de la Dirección del Trabajo (julio de 2002), p. I2. 
colectiva que afecten a un determinado colectivo de funcionarios. ${ }^{7}$ Generalmente tal regulación se concreta en un estatuto general que consagra los principios universales de la función pública y un catálogo de derechos, obligaciones y prohibiciones de los funcionarios, y diversos estatutos particulares que concretizan la regulación de los derechos, deberes y responsabilidades de los funcionarios de acuerdo con las particularidades del servicio público en el que se desempeñan. ${ }^{8}$

Bajo esta configuración — modelo estatutario de función pública- se evita que el servicio público sea capturado por intereses corporativos de los mismos servidores públicos, así como por intereses de los titulares más o menos pasajeros del poder. La finalidad, según nos explica VaLdivia, es que los empleados públicos no sean un botín de los partidos políticos que se turnan en el gobierno. ${ }^{9}$

\section{Chile y el modelo estatutario de función pública}

Para el caso de nuestro país, la doctrina administrativista tradicionalmente ha sostenido que rige un sistema estatutario, toda vez que la relación laboral entre los empleados y la Administración es regulada por un estatuto jurídico de carácter público, totalmente diferenciado del régimen laboral común. De esta manera, la relación laboral que une al Estado con su personal es regulada por un régimen jurídico que es determinado exclusiva y unilateralmente por la ley y, como señala Jeze, el acuerdo de voluntades que nace cuando la persona designada acepta su cargo, no origina un contrato creador de derechos y obligaciones, sino que tan solo produce el efecto jurídico de aplicar a un individuo un estatus legal y reglamentario determinado. ${ }^{10}$

7 Los orígenes de este modelo lo encontramos en el derecho francés, consolidado en la época de la revolución francesa, donde la idea central era la creación de instituciones estables, permanentes y duraderas. En razón de ello, el funcionario es considerado como un defensor del interés general, con un fuerte vínculo con el Estado, pero alejado de las luchas políticas existentes. Está sujeto a estrictas reglas disciplinarias y debe desempeñar su cometido con total lealtad, a cambio de lo cual se le garantiza, esencialmente, la expectativa cierta de hacer carrera por antigüedad y mérito y la inamovilidad en su cargo. SÁnchez Morón, Miguel, Derecho de la función pública (5. ${ }^{\mathrm{a}}$ edición, España, Editorial Tecnos, 2008), p. 26.

8 Parada, Ramón, Derecho Administrativo (Madrid, Editorial Marcial Pons, 1998), III, p. 397.

9 Valdivia, José Miguel, Manual de Derecho Administrativo (Valencia, Tirant lo Blanch, 20I8), p. I06.

10 Jeze, Gastón, Principios generales del Derecho Administrativo (Buenos Aires, Editorial Depalma, 1948-1950), p. 48. Siguen el postulado de la tesis estatutaria autores como 
El origen histórico de la idea de Estatuto Administrativo como fuente reguladora de la situación jurídica de los trabajadores del sector público en Chile lo podemos encontrar en las discusiones que se generaron al interior de la Comisión Constituyente de la Constitución de 1925. ${ }^{\text {II }}$ El objetivo de su consagración era la eliminación de las influencias políticas y las arbitrariedades en la designación de los empleados públicos, ${ }^{12}$ y debido a ello fue que el Constituyente de 1925 pretendió garantizar que los nombramientos y ascensos fuesen fruto de una selección cuidadosa bajo las condiciones de idoneidad que debía determinar el Estatuto Administrativo. ${ }^{13}$

En esa oportunidad, el expresidente Alessandri postuló que había que hacer un gran distingo en materia de nombramientos. Por una parte, están aquellos funcionarios que nombra el presidente de la República a su voluntad, como ministros, intendentes, gobernadores y jefes de oficina. Por otra, los demás empleados civiles y militares que determinarán las leyes. Estos los nombraría el presidente, pero no discrecionalmente, sino que conforme al Estatuto Administrativo. ${ }^{\mathrm{I}}$

Si bien en las discusiones de la Comisión de la Constitución de 1925 no hay un gran desarrollo de lo que se entendería por Estatuto Administrativo, a los pocos meses de publicada' ${ }^{15}$ se dictó el Decreto Ley 74I de

Silva Cimma, quien precisa que el régimen estatutario que rige al personal del Estado es de carácter general e impersonal, es decir, se trata de un régimen establecido a priori por el legislador, antes del ingreso de un funcionario a un servicio público determinado, sin hacer distingos en base a las situaciones particulares de cada uno de ellos. Silva Cimma, Enrique, Derecho Administrativo chileno y comparado (Santiago, Editorial Jurídica de Chile, 1993), p. Ir3-II4. En el mismo sentido, Caldera Delgado, Hugo, Manual de Derecho Administrativo (Santiago, Editorial Jurídica de Chile, 1979), p. 299.

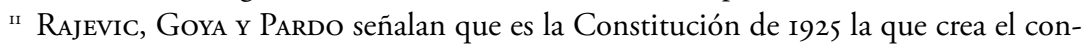
cepto de Estatuto Administrativo, regulación que se ha mantenido y desarrollado hasta la actualidad. Rajevic, Enrique; Goya, Felipe y Pardo, Carlos, Los puestos directivos en el Estado Chileno. Hacia un sistema de gerencia pública (Santiago, Centro de Estudios Públicos, 2002), II, p. 53.

${ }_{12}$ Se quería evitar el sistema conocido como spoilsystem o sistema de botín, donde el partido político que ganaba las elecciones despedía al personal de la administración anterior y contrataba a los de su sector, pagando de esa forma favores políticos. PARADA, Ramón, Derecho Administrativo II. Organización y empleo público (Madrid, Editorial Marcial Pons, 1996).

${ }^{13}$ Marín Vallejo, Urbano, cit. (n. 4), p. 216.

${ }^{14}$ Soтo Kloss, Eduardo, La idea institucional del Estatuto Administrativo en el Derecho Chileno, en Revista de Derecho Público 25-26 (1979), pp. 99 y ss.

is La Constitución Política de i925 fue publicada el i8 de septiembre de 1925, tras ser aprobada en el plebiscito de 30 de agosto de 1925 . Las normas que consagran el principio de Estatuto Administrativo fueron el artículo 72 número 7, que establecía que la provisión de los demás empleos civiles y militares que determinen las leyes que es de competencia 
diciembre de 1925, relativo al «Estatuto Administrativo o Ley Orgánica de los Funcionarios Civiles del Estado», en el que, además de regularse su ámbito de aplicación y los requisitos para el nombramiento o designación de los funcionarios, se estableció una regulación estable, permanente y orgánica de la relación funcionarial, que comprende lo relativo a ascensos, permutas, reincorporaciones, reemplazos, comisiones, traslados, incompatibilidades, licencias, feriados, sueldos, asistencia, duración del trabajo, régimen disciplinario, expiración de funciones, y, en general, todo el cuerpo de deberes, responsabilidades y derechos de los funcionarios. ${ }^{16}$ Posteriormente, el Decreto Ley 74I es reemplazado por el Decreto con Fuerza de Ley 338 del 5 de abril de 1960, que fija un nuevo Estatuto Administrativo.

La Constitución de 1925, por tanto, fue la precursora en el establecimiento de un sistema de empleo público, ya que bajo la anterior Constitución (de I833), el presidente de la República proveía la generalidad de los empleos civiles, sin sujeción a norma estatutaria alguna.

Con la dictadura militar del año 1973 se produce un quiebre del modelo: se dispuso que todo el personal de los servicios, reparticiones, organismos, empresas y demás instituciones del Estado, tanto central como descentralizada, con excepción del Poder Judicial y la Contraloría General de la República, pasarían a tener la calidad de empleados interinos. ${ }^{17}$ Esta norma, como explica Rajevic, fue reforzada por el Decreto con Fuerza de Ley 2.345 del 20 de octubre de 1978 , al permitir la remoción presidencial, previa propuesta del ministro del Interior, «de cualquier funcionario que fuese necesario para desburocratizar la Administración del Estado». ${ }^{18}$

La misma dictadura, tras la entrada en vigor de la Constitución Política de 1980 , reconstruye el modelo ${ }^{19}$ al consagrar el principio de igualdad en el acceso a los empleos y cargos públicos según el mérito y capacidad, y establecer una reserva de ley en cuanto al régimen jurídico de los funcionarios

del Presidente de la República deberá efectuarse «conforme al Estatuto Administrativo»; el artículo 72 número 8, cuando refería que la destitución de los empleos subalternos ha de efectuarse con informe de la autoridad respectiva «en conformidad a las leyes orgánicas de cada servicio" y, finalmente, el artículo 72 número 9, cuando disponía que la concesión de jubilaciones, retiros o montepíos, ha de hacerse "con arreglo a las leyes». Ibíd., p. IO5.

${ }^{16}$ Soto Kloss, Eduardo, cit. (n. I4), pp. I04 y I05.

${ }^{17}$ Artículo I del Decreto Ley 6 de 1973, promulgado el I2 de septiembre de 1973 y publicado el i9 de septiembre de 1973 .

${ }^{18}$ Rajevic, Enrique, La crisis de la regulación del empleo público en Chile. Ideas para un nuevo modelo, en Aninat, Isabel y Razmilic, Slaven (eds.), Un Estado para la ciudadanía. Estudios para su modernización (Santiago, Centro de Estudios Públicos, 2018), p. 405.

19 Ibíd., p. 406. 
públicos. En efecto, el artículo 38 de la Constitución Política dispone que una ley orgánica constitucional deberá garantizar «la carrera funcionaria y los principios de carácter técnico y profesional en que deba fundarse, y asegurará tanto la igualdad de oportunidades de ingreso a ella como la capacitación y el perfeccionamiento de sus integrantes».

Restableciendo el camino iniciado por la Constitución de 1925, se encomienda a una ley orgánica constitucional la función de determinar la organización básica de la Administración Pública, garantizar la carrera funcionaria y los principios de carácter técnico y profesional en que deba fundarse, y asegurar tanto la igualdad de oportunidades de ingreso a ella como la capacitación y el perfeccionamiento de sus integrantes.

En cumplimiento del mandato constitucional, se dictó la Ley i8.575 sobre Bases Generales de la Administración del Estado, la que consagró el sistema estatutario al disponer que el personal de la Administración del Estado se regirá por las normas estatutarias que establezca la ley. ${ }^{20}$ Asimismo, consagró las bases y los principios de la carrera funcionaria, ${ }^{2 \mathrm{I}}$ disponiendo que el Estatuto Administrativo regulará la carrera funcionaria y considerará especialmente los principios de ingreso por concursos objetivos; sistema de carrera de carácter técnico, profesional y jerárquico; los deberes y los derechos de los funcionarios; la responsabilidad administrativa; la relevancia de la capacitación y perfeccionamiento y la cesación de funciones teniendo en vista el principio de estabilidad en el empleo. Por otro lado, reconoció la posibilidad de crear estatutos de carácter especial para determinadas profesiones o actividades, cuando las características de su servicio lo requieran, estatutos que deberán ajustarse a las disposiciones establecidas por la misma. ${ }^{22}$

Así, la regulación unilateral, general e impersonal de la relación jurídica que une a la Administración y sus empleados está contenida principalmente en la Ley i8.834 sobre Estatuto Administrativo, que conforme lo establece su artículo I regula las relaciones entre el Estado y su personal, principalmente en lo que dice relación con el acceso, nombramiento, derechos, obligaciones, responsabilidades y cesación de funciones.

Cabe precisar que el Estatuto Administrativo no tiene la exclusividad en la regulación del trabajo en el Estado, toda vez que el panorama normativo chileno muestra que existe una diversidad de normas aplicables a los

${ }^{20}$ Artículo is de la Ley 18.575: "El personal de la Administración del Estado se regirá por las normas estatutarias que establezca la ley, en las cuales se regulará el ingreso, los deberes y derechos, la responsabilidad administrativa y la cesación de funciones».

${ }^{21}$ Párrafo 2, artículos 43 y siguientes, de la Ley 18.575.

${ }^{22}$ Artículo 43 de la Ley I8.575. 
funcionarios públicos, entre ellas, el propio Código del Trabajo. De esta manera, la uniformidad anhelada por el constituyente de 1980 no es tal, ya que en nuestro sistema de empleo público existen diversos regímenes jurídicos que regulan la relación entre el Estado y su personal. Según MARín Vallejo, el personal de la Administración del Estado no está sujeto a una misma y única normativa, ya que en ella coexisten diversos cuerpos jurídicos que pueden tener una aplicación generalizada a ciertos sectores, o bien, limitada a determinados organismos, o incluso, a determinadas categorías de funcionarios de una misma institución. Para el autor, la diversidad normativa aplicable a los funcionarios del Estado denota una tendencia a reducir el campo de aplicación de las normas propiamente estatutarias en la Administración estatal, las que estarían siendo sustituidas por la legislación laboral. ${ }^{23}$

El modelo de empleo definido por el Estatuto Administrativo es el de planta, esto es, "el conjunto de cargos permanentes asignados por ley a cada institución». ${ }^{24}$ De esta manera, el empleo en la Administración del Estado debía construirse en base al funcionario de carrera, con estabilidad laboral, única forma de proyectar un servicio público eficiente y de calidad, que no esté condicionado a los cambios políticos de los gobiernos de turno. Como expresa Rajevic, la construcción del modelo de empleo público en base al funcionario de carrera reduce la discrecionalidad de la autoridad en el ingreso, promoción y remoción, dando cumplimiento al mandato constitucional de fundar la carrera en principios de carácter técnico y profesional. ${ }^{25}$ De forma marginal —al menos desde el punto de vista teórico-, se contemplaron dos figuras adicionales: el empleo a contrata ${ }^{26}$ y la contratación a honorarios. ${ }^{27}$ Estas figuras confieren a la autoridad notables dosis de discrecionalidad, toda vez que son cargos provistos sin concurso público y se pueden remover sin necesidad de una investigación o sumario administrativo previo.

${ }^{23}$ Marín Vallejo, Urbano, cit. (n. 4), pp. 201 y 203.

${ }^{24}$ Artículo 3 letra b) del Estatuto Administrativo.

${ }_{25}$ Rajevic, Enrique, cit. (n. I8), p. 408.

${ }^{26}$ De acuerdo con lo señalado por los artículos 3 letra d) y io del Estatuto Administrativo, el empleo a contrata es de carácter transitorio, su duración no puede exceder al $3 \mathrm{I}$ de diciembre de cada ańo, con posibilidad de prórroga, estableciéndose un tope numérico o dotación máxima del $20 \%$ del total de los cargos de la planta respectiva.

${ }^{27}$ El artículo in del Estatuto Administrativo faculta a la autoridad a contratar a personas naturales a honorarios, únicamente para la realización de tareas accidentales y que no sean habituales para la institución o para la realización de cometidos específicos. 


\section{SUPERANDO LA TESIS DEL DIVORCIO: EL FENÓMENO DE LABORALIZACIÓN DE LA FUNCIÓN PÚBLICA}

Nadie podría negar que el derecho del trabajo nació para regular las relaciones entre empleadores y trabajadores del sector privado, por lo que su ámbito de acción originario no alcanzó a los trabajadores autónomos o a los trabajadores del sector público. ${ }^{28}$ Sin embargo, con el transcurso del tiempo, el derecho del trabajo fue desbordando las fronteras del trabajador asalariado del mundo privado debido a la atracción que ejerce sobre las otras formas de trabajo humano, especialmente cuando dicho trabajo carece de un estatuto protector o, existiendo un estatuto específico, este es insuficiente. ${ }^{29}$

\section{Breve nota conceptual}

El fenómeno conocido como laboralización de la función pública hace referencia a la expansión que ha tenido el derecho del trabajo al mundo de la función pública, superando con ello el tradicional divorcio que se marcaba entre la regulación del empleo en el sector público de la regulación del empleo del sector privado. ${ }^{30}$

Siguiendo a Binder, el fenómeno de laboralización tiene dos dimensiones. Por un lado, una dimensión fuerte, que implica la sustitución total del régimen de función pública por el derecho del trabajo: los trabajadores estatales quedan sometidos a la normativa laboral del mundo privado. ${ }^{31}$

${ }^{28}$ Supiot, Alain, cit. (n. I), p. Io.

29 Según Gamonal Contreras, el derecho del trabajo paulatinamente fue ampliando su ámbito de protección desde el trabajador subordinado del sector privado hacia los trabajadores de las empresas del Estado, trabajadores independientes e, incluso, a los funcionarios públicos. Gamonal Contreras, Sergio, Trabajo y derecho (Santiago, Thomson Reuters, 20I0), p. I59.

${ }^{30}$ Como indica Parada, «la función pública y el régimen laboral son materias movedizas y fluctuantes en donde lo que hoy es un elemento diferencial entre una y otra, mañana puede dejar de serlo o estar en trance de desaparición». PARAdA, Ramón, cit. (n. 8), p. 386.

${ }^{31}$ En Italia, por ejemplo, el modelo de función pública tradicional estuvo inmerso en el fenómeno de laboralización, que comenzó — precisamente — con la aplicación de instituciones más típicas del derecho laboral: la negociación colectiva. Con el paso del tiempo dicha expansión llegó hasta la asimilación absoluta de los funcionarios públicos a los trabajadores del sector privado. Parada, Ramón, cit. (n. 8), p. 4II. Binder da cuenta de que luego de las reformas de 1992-1993 y 1997-I998, la relación de servicio público transformó su naturaleza estatutaria o unilateral a una contractual, unificándose el empleo público y privado en un solo régimen jurídico, salvo determinadas categorías de funcionarios (magistrados, abogados del Estado, personal militar y fuerzas de policía, diplomáticos, 
Por otro lado, una dimensión débil, en la que el fenómeno de laboralización implica introducir instituciones que son propias del derecho del trabajo a la regulación del empleo público, sin que exista, por tanto, una total huida del derecho administrativo. ${ }^{32}$

En términos generales, entonces, el fenómeno de laboralización de la función pública consiste en el arribo del derecho del trabajo a través de sus instituciones más características, a tierras que eran propias del derecho administrativo, ${ }^{33}$ con lo que se pone en jaque la tradicional tesis de división o separación de regímenes.

Este proceso de expansión del derecho del trabajo hacia el empleo público se ha manifestado, por un lado, en la admisión de personal laboral al servicio de las Administraciones públicas (contratación bajo las normas del derecho del trabajo) y, por otro, en el reconocimiento (normativo o de facto) del ejercicio de derechos fundamentales que tradicionalmente estaban reservados a los trabajadores del sector privado, derechos que excluían a los empleados públicos de su ejercicio en razón del carácter legal o reglamentario de su estatuto jurídico. Nos referimos a los derechos de negociación colectiva y huelga.

\section{Chile y el tránsito hacia la laboralización}

Chile no está ajeno al fenómeno de laboralización descrito. El Código del Trabajo - normativa que regula la relación de trabajo del sector privado- ocupa importantes roles al interior del sistema de función pública chileno.

En primer lugar, el Código del Trabajo opera como norma supletoria general del trabajo humano prestado en condiciones de subordinación, ${ }^{34}$ por lo que, en todo lo no regulado por el estatuto que rija a los fun-

prefectos, directores generales y equiparados y secretarios municipales y provinciales). BINDER, Jaime, cit. (n. 6), pp. I5-I6.

${ }_{32}$ Binder, Jaime, cit. (n. 6), p. I4.

${ }_{33}$ Sobre los diversos aspectos y significados que tiene el proceso de laboralización de la función pública puede revisarse la vasta doctrina española sobre la materia, entre otros: Sala Franco, Tomás, Incidencia de la legislación laboral en el marco de la función pública (Madrid, Inap, 1989); Cantero Martínez, Josefa, El empleo público: entre el estatuto funcionarial y el contrato laboral (Barcelona, Editorial Marcial Pons, 200I); IzQUIERDo Hernández, Francisco Javier, y Molina García, Mónica, La laboralización de los funcionarios públicos (Valencia, Tirant Lo Blanch, 1996).

${ }^{34}$ Como indican Thayer Arteaga y Novoa Fuenzalida, «la legislación del trabajo aparece como el derecho común regulador de las prestaciones de servicios, nota típica de su carácter expansivo». Thayer Arteaga, William, y Novoa Fuenzalida, Patricio, Derecho del Trabajo (Santiago, Editorial Jurídica de Chile, 1998), II, p. I4. 
cionarios públicos, se aplicará la normativa laboral común. ${ }^{35}$ En segundo término, determinadas instituciones que están reguladas en el Código del Trabajo tienen aplicación directa para los trabajadores del sector público, como es la normativa protectora a la maternidad, paternidad y vida familiar. ${ }^{36}$ Como tercer punto, existen trabajadores públicos cuyo estatuto jurídico es el Código del Trabajo, lo que significa que en nuestro sistema de función pública existen trabajadores sujetos a la normativa estatutaria y otros sujetos a la normativa laboral común; rige, por tanto, un sistema mixto. ${ }^{37}$ Finalmente, porque al menos en el plano fáctico, se aplicación instituciones propias del derecho del trabajo, como los derechos de negociación colectiva y huelga.

Si nos preguntamos por cuáles han sido los factores que han influido en este proceso de laboralización de la función pública, la verdad es que son difíciles de detectar, ya que no ha existido un tránsito ordenado y coherente de un sistema a otro, y se ha impuesto desde los inicios más bien un desorden en cuanto a los regímenes jurídicos que conviven al interior de la Administración Pública. ${ }^{38}$

Quizá una de las causas de la creciente incorporación de instituciones del derecho del trabajo al ámbito público o la aplicación de garantías laborales al momento de dirimir conflictos especialmente vinculados con el cese de funciones, viene dada por la constante precarización del empleo público. Como explica Rajevic, el personal de carrera, que según la Constitución debiese ser el corazón del sistema, ha ido retrocediendo dramáti-

${ }_{35}$ El carácter de legislación supletoria se deriva de lo dispuesto en el inciso tercero del artículo I del Código del Trabajo.

${ }^{36} \mathrm{El}$ artículo 89 inciso segundo del Estatuto Administrativo dispone: «Asimismo, tendrá derecho a gozar de todas las prestaciones y beneficios que contemplen los sistemas de previsión y bienestar social en conformidad a la ley y de protección a la maternidad, de acuerdo a las disposiciones del Título II, del Libro II, del Código del Trabajo».

${ }_{37}$ Despojando al Estatuto Administrativo de su vocación de generalidad, el Código del Trabajo irrumpe en forma directa en la función pública, ya no bajo el pretexto de vacío u omisión de regulación, sino como estatuto especial, es decir, aplicándose de forma directa en la regulación de la relación laboral entre el Estado y el personal de determinados servicios u organismos públicos. Si bien en la actualidad no existe una norma general que faculte a la Administración del Estado a contratar personal bajo las reglas del Código del Trabajo, han sido las propias leyes orgánicas de los servicios las que sujetan la regulación de la relación laboral de su personal a las normas del Código del Trabajo.

${ }^{38}$ En efecto, ya en el año 1948, la Contraloría General de la República sostuvo que no existe un único cuerpo orgánico estatutario, sino que hay varios para las distintas clases de funcionarios, todos los cuales están comprendidos en la noción institucional de estatuto administrativo. Entre otros pronunciamientos, tal criterio está contenido en el Dictamen I5.4I2, de I4 de abril de 1948 . 
camente, y ha llegado a transformarse en una categoría minoritaria o en envejecimiento. ${ }^{39}$ Esta disminución no ha sido consecuencia de un proceso de reducción del aparato estatal, y, por ende, del personal al servicio del Estado, al contrario, el empleo público ha ido creciendo sostenidamente, pero en base a categorías precarias: la contrata y los honorarios.

Ante esta realidad y la insuficiente protección que entrega la norma estatutaria al personal a contrata y a las personas naturales que prestan servicios a honorarios, los tribunales de justicia y el propio órgano contralor ${ }^{40}$ han ido construyendo líneas jurisprudenciales que aplican instituciones y/o principios del derecho del trabajo, con el objetivo de brindar tutela a los trabajadores del Estado. Como advierte Rajevic, desde el 2015 la Corte Suprema ha empezado a aplicar garantías del derecho laboral común al personal a contrata y honorarios, específicamente, la acción de tutela de derechos fundamentales y, para el caso del personal a honorarios que presta sus servicios bajo subordinación y dependencia, la posibilidad de que esa relación sea declarada como laboral, aplicándose con ello todo el estatuto protector del Código del Trabajo, en especial, la batería de sanciones ante despidos injustificados. ${ }^{4 \mathrm{I}}$

Más allá de este desorden, lo relevante en este punto es que el Código del Trabajo cumple importantes roles o funciones en el ámbito del empleo público, una de ellas, la de ser legislación supletoria. En los últimos años, la referida función supletoria ha cobrado una importancia crucial, especialmente a propósito de la tutela o protección de los derechos fundamentales de los trabajadores públicos, producto de la incorporación al Código del Trabajo de una acción específica destinada a resguardar tales derechos durante la vigencia de la relación laboral o con ocasión de su término.

En lo que sigue de este artículo ahondaremos en la primera de estas funciones - legislación supletoria—, específicamente en relación a la aplicación de la acción de tutela de derechos fundamentales a los trabajadores públicos regidos por normas estatutarias, ya que, luego de un arduo debate jurisprudencial y criterios zigzagueantes, se aprobó la Ley 21.28o, que

39 Rajevic, Enrique, cit. (n. I8), p. 409.

${ }^{40}$ Con la llegada del actual Contralor General de la República se produjo un vuelco radical en la doctrina administrativista vinculada con las problemáticas que afectan al personal a contrata, especialmente ante el término anticipado de la contrata o su no renovación. El dictamen clave en este sentido fue el 22.766 de 20I6, que introduce los criterios de la confianza legítima y del acto fundado. En relación con el personal a honorarios, el dictamen que más destaca es el que hizo aplicable los derechos referidos a la protección de la maternidad contenidos en el Código del Trabajo a las trabajadoras contratadas a honorarios que prestan servicios habituales (Dictamen I4.498 de 2019).

${ }^{41}$ Ibíd., pp. 4IO-4II. 
vino a dirimir este debate a favor de la aplicación de la acción de tutela de derechos fundamentales a todos los trabajadores, incluidos los del sector público.

\section{TUTELA DE DERECHOS FUNDAMENTALES Y FUNCIÓN PÚBLICA: UNO DE LOS FLANCOS DEL FENÓMENO DE LABORALIZACIÓN DE LA FUNCIÓN PÚBLICA EN CHILE}

La Ley 2I.280 tiene una clara inclinación por la laboralización de la función pública, al menos en su sentido débil, ya que hace aplicable una acción judicial regulada por la legislación laboral común a los trabajadores públicos, confiriendo competencia expresa a los Juzgados del Trabajo para conocer tales conflictos. Con esta definición se derriba la tesis de que los derechos fundamentales en el ámbito del empleo público deben tener un tratamiento diferenciado, no solo en relación con su ejercicio, sino que también respecto de su oponibilidad y mecanismos jurídicos de tutela. ${ }^{42}$

De esta manera, la ley deja claro que, independientemente de que los empleados públicos están sometidos a una relación especial de sujeción y un régimen legal de carácter estatutario, son titulares de derechos fundamentales, los que no pueden tener un estatus diferente al de la generalidad de los trabajadores.

\section{Derechos fundamentales y tutela judicial}

Como señala nuestra doctrina, tradicionalmente el derecho del trabajo ha cumplido la función de establecer condiciones laborales mínimas, socialmente aceptables, para el desenvolvimiento de la relación existente entre empleador y trabajador, asumiendo como premisa básica que este último tiene la calidad de contratante débil. ${ }^{43}$ Con el correr del tiempo, las funciones asignadas a esta especial rama del derecho han ido en expansión, tutelándose, además de los derechos laborales propiamente tales —esos mínimos socialmente aceptables_- los derechos fundamentales del trabajador.

Estas nuevas funciones asignadas a esta especial rama del derecho vienen de la mano con la doctrina de la eficacia horizontal de los derechos fundamentales, la cual, superando la tradición jurídica que entendía que las normas constitucionales sobre derechos fundamentales se aplicaban

42 Díaz, Cecilia, ¿Tutela laboral de funcionarios públicos? (Santiago, Editorial Libromar, 20I9), p. 3I.

${ }^{43}$ Gamonal Contreras, Sergio, Lineamientos de derecho del trabajo (Santiago, Lexis Nexis, 2006), p. 108. 
únicamente a las relaciones entre los ciudadanos y el Estado, sostuvo que los particulares, en el marco de sus relaciones privadas, podían esgrimir contra otros particulares los derechos fundamentales consagrados en los textos constitucionales. ${ }^{44}$ Lo anterior se explica por una razón bastante sencilla: siempre que existan relaciones entre particulares basadas en asimetrías de poder se abrirá un flanco para el ejercicio abusivo y la posible afectación de los derechos fundamentales de la persona que está en una posición desventajada.

En la doctrina laboral, la eficacia horizontal de los derechos fundamentales se justificó precisamente en ello: se trata de una relación donde el poder está desigualmente distribuido, por lo que, de alguna manera, se reproducía la diferencia que existe entre el Estado y los ciudadanos. Ante esta asimetría de poder se hacía necesario consagrar mecanismos de resguardo para los trabajadores, quienes, ante el poder ejercido por el empleador, podían ver lesionados sus derechos fundamentales. ${ }^{45}$

Para el caso chileno, la eficacia horizontal de los derechos fundamentales se encuentra consagrada expresamente en el artículo 6 inciso segundo de la Constitución Política, al señalar que «los preceptos de esta Constitución obligan tanto a los titulares o integrantes de dichos órganos como a toda persona, institución o grupo». A nivel legal, y en lo que a nuestra disciplina se refiere, se encuentra recogida en el artículo 5 inciso primero del Código del Trabajo, el que dispone que «el ejercicio de las facultades que la ley reconoce al empleador, tiene como limite el respeto a las garantías constitucionales de los trabajadores, en especial cuando pudieran afectar a la intimidad, vida privada u honra de estos». ${ }^{46}$

Actualmente, el reconocimiento de los derechos fundamentales como garantías plenamente exigibles al interior de la relación laboral dispone de

44 Ugarte, José Luis, Derechos fundamentales en el contrato de trabajo (Santiago, Legal Publishing, 20I3), pp. 8-9. PeÑa ha definido esta eficacia horizontal como «la posibilidad de que los particulares esgriman, en contra de otros particulares y en el ámbito de las relaciones privadas, los derechos subjetivos públicos como, por ejemplo, el derecho de propiedad, el derecho a no ser discriminado, la libertad de emitir opinión, el derecho a la intimidad o el derecho moral de autor». PEÑA, Carlos, Sistema jurídico y derechos humanos (Santiago, Universidad Diego Portales, 1996), p. 668.

45 Siguiendo a Ugarte, la doctrina de la eficacia horizontal de los derechos fundamentales o Drittwirkung, se justifica en "la existencia de relaciones sociales que reproducen, en alguna medida, el poder que originalmente ejercía el Estado sobre los ciudadanos». Sobre la base de lo anterior, el autor postula que un caso paradigmático de ejercicio de ese poder fuera de la relación Estado-ciudadano es el que ejerce el empleador en el marco de la relación laboral. Ugarte, José Luis, cit. (n. 44), pp. I2 y 22.

${ }^{46}$ Disposición incorporada en el año 200I por medio de la Ley 19.759. 
una herramienta procesal específica para recabar su tutela, dejando atrás la falencia de que adolecía la normativa laboral en esta materia por la falta de mecanismos procesales específicos e idóneos que hicieran operativas las normas en referencia. ${ }^{47}$ En efecto, el artículo 485 del Código del Trabajo señala que las garantías fundamentales del trabajador se encuentran protegidas por medio del procedimiento de tutela laboral, o más bien, la acción de tutela de derechos fundamentales..$^{8}$

De esta manera, el ordenamiento jurídico laboral protege tanto los derechos fundamentales específicos del trabajador - aquellos que protegen su actividad organizativa (sindicación, negociación colectiva y huelga, principalmente) - y los derechos fundamentales inespecíficos - aquellos que protegen al trabajador en su calidad de ciudadano. ${ }^{49}$

Ahora, no se protege todo el catálogo de garantías constitucionales del artículo in de la Constitución Política, sino que única y exclusivamente las que enuncia el artículo 485 del Código del Trabajo. Se trata, por tanto, de una protección selectiva que recae sobre las siguientes garantías constitucionales: el derecho a la vida y a la integridad física y psíquica de la persona, siempre que su vulneración sea consecuencia directa de actos ocurridos en la relación laboral; el respeto y protección a la vida privada y a la honra de la persona y su familia; la inviolabilidad de toda forma de comunicación privada; la libertad de conciencia, la manifestación de todas las creencias y el ejercicio libre de todos los cultos que no se opongan a la moral, a las buenas costumbres o al orden público; la libertad de emitir opinión y la de informar, sin censura previa, en cualquier forma y por cualquier medio; la libertad de trabajo, el derecho a su libre elección; el derecho a la no discriminación, con la limitante de que no se tutelan aquellas acciones de discriminación perpetradas antes de que exista vínculo laboral (ofertas de trabajo); la libertad sindical ${ }^{\circ o}$ y la denominada garantía

47 Ugarte, José Luis, El nuevo derecho del trabajo (Santiago, Lexis Nexis, 2007), p. I24.

${ }^{48}$ Es necesario advertir que la referida tutela está prevista exclusivamente para el listado de derechos fundamentales seńalados en el artículo 485 del Código del Trabajo.

49 En cuanto a la importancia de la protección de estos derechos al interior de la relación laboral, Gamonal nos señala que como la relación de trabajo no conlleva una coordinación entre pares, sino que más bien, un vínculo de sumisión o una relación de poder de un sujeto privado sobre otro, se está ante un ambiente propicio para los abusos de poder, y, por ende, para la probable lesión de algunos derechos fundamentales del sujeto subordinado, situación que demanda de una adecuada tutela. Gamonal Contreras, Sergio, Ciudadanía en la empresa o los derechos fundamentales inespecificos (Montevideo, Fundación de Cultura Universitaria, 2004), p. I4.

so Ello, en virtud de la remisión realizada por el inciso cuarto del artículo 292 del 
de indemnidad, esto es, el derecho a no ser objeto de represalias por haber ejercido acciones judiciales o administrativas contra el empleador.

\section{2. ¿Quiénes pueden ejercer la acción de tutela?}

El artículo 485 del Código del Trabajo dispone que la acción de tutela se aplicará a las «cuestiones suscitadas en la relación laboral por aplicación de las normas laborales, que afecten los derechos fundamentales de los trabajadores", redacción que a primera vista nos lleva a concluir que es una acción pensada para los trabajadores del sector privado, cuestión que sería concordante con el ámbito de aplicación del Código del Trabajo que fija el inciso primero de su artículo I.

En relación con el tema de la titularidad, previo a la dictación de la Ley 2I.280 existió un intenso debate doctrinal y jurisprudencial en torno a si la referida acción podía ser ejercida por funcionarios públicos. Para algunos, se trataba de una acción aplicable exclusivamente a los trabajadores sujetos al Código del Trabajo, ${ }^{\text {,I }}$ en tanto que otros, sobre la base del carácter supletorio de la legislación laboral (inciso tercero del artículo I del Código del Trabajo) y la insuficiente protección que brinda el Estatuto Administrativo en esta materia, estimaron que los funcionarios públicos eran titulares activos de la acción de tutela de derechos fundamentales.

La tesis a favor de la aplicación de la acción de tutela estructuró su argumento de la siguiente manera: si bien el ámbito propio de acción del Código del Trabajo es la regulación de las relaciones laborales entre los empleadores y trabajadores del sector privado (inciso primero del artículo I), estando excluidos los trabajadores del Estado (inciso segundo del artículo I); estos se sujetarán de todos modos a las normas del Código del Trabajo «en los aspectos o materias no regulados en sus respectivos estatutos, siempre que ellas no fueren contrarias a éstos últimos» (inciso tercero del artículo I)..$^{22}$

Entonces, para determinar si los trabajadores públicos pueden o no

Código del Trabajo, a propósito de la sanción de las prácticas antisindicales.

${ }^{51}$ Esta es la postura defendida por Díaz, quien señala que de los artículos 485, 486 y 489 del Código del Trabajo se desprende como requisito para la aplicación de la acción de tutela que se trate de trabajadores dependientes regidos por el Código del Trabajo y no así por estatutos especiales. DíAz, Cecilia, cit. (n. 42), p. 90.

52 La referida disposición, además de fijar los límites de la aplicación del Código del Trabajo al sector público, reviste una vital importancia, ya que de sus declaraciones se desprende que el Código del Trabajo constituye el derecho común aplicable a todos los trabajadores dependientes, y, por ende, que los estatutos especiales de los funcionarios públicos tendrán el carácter de leyes especiales en relación con el Código del Trabajo. Marín Vallejo, Urbano, cit. (n. 4), p. 240. 
ejercer la acción de tutela había que hacerse dos preguntas centrales: primero, ¿contempla el Estatuto Administrativo alguna acción judicial cuyo propósito sea tutelar al empleado público frente a eventuales lesiones de sus derechos fundamentales, como la vida privada, no discriminación, etcétera? Segundo, una vez que detectamos la omisión o vacío legal de la norma estatutaria debemos preguntarnos: ¿es la acción de tutela de derechos fundamentales compatible con la norma estatutaria?

En respuesta a estas interrogantes, la tesis proclive a la aplicación de la acción de tutela al ámbito público sostenía que el Estatuto Administrativo no consagraba ninguna herramienta judicial para tutelar al funcionario que había visto lesionados sus derechos fundamentales, sea en el desarrollo de la relación laboral o con ocasión de su término..$^{53}$ Posteriormente, entraba en escena el citado inciso tercero del artículo i del Código del Trabajo, y debían aplicarse supletoriamente los artículos 485 y siguientes del Código del Trabajo al existir un vacío legal en la materia.

En relación con la segunda de las interrogantes se sostenía que había una total compatibilidad, ya que la acción de tutela pretende poner fin a actos lesivos de derechos fundamentales, derechos de los que son titulares todas las personas, incluidos los funcionarios públicos, y el Estado es el primer obligado en respetarlos. En otros términos, las normas del procedimiento de tutela laboral en ningún caso pueden ser consideradas contrarias a los estatutos de los empleados públicos, toda vez que su objetivo es el efectivo resguardo y protección de los derechos fundamentales del cual son titulares todas las personas sin distinción. Aplicando los criterios de interpretación propios de los derechos fundamentales, en concreto, el principio pro homine o pro civis, ${ }^{54}$ debemos preferir aquella interpretación que extienda al máximo el alcance de un derecho fundamental, y, a la inversa, se debe optar por la interpretación más restringida cuando se trata de establecer limitaciones al ejercicio de estos. En consecuencia, este prin-

${ }^{3} \mathrm{La}$ única referencia que se hace a un derecho fundamental es respecto al atentado que pueden realizar terceras personas en contra de la vida o integridad corporal de los funcionarios, con motivo del desempeño de sus funciones, confiriéndoles el derecho a ser defendidos y exigir que la institución a que pertenezcan persiga la responsabilidad civil y criminal de los responsables (artículo 84 del Estatuto Administrativo).

${ }_{54}$ Este principio tiene un reconocimiento expreso en la Convención Interamericana de Derechos Humanos o Pacto de San José de Costa Rica, específicamente en su artículo 29, relativo a las normas de interpretación, en el sentido de que ninguna norma de la Convención, así como cualquier otro instrumento internacional o leyes de los Estados partes, puede ser interpretada de manera que se suprima el goce y ejercicio de los derechos y libertades reconocidos en tales instrumentos, o se los limite en mayor medida que lo previsto en ellos. 
cipio nos ordena dar una aplicación preferente a la norma más favorable a la persona humana, y no cabe duda de que, en el caso en comento, la interpretación más favorable es aquella que permite el ejercicio de la acción de tutela de derechos fundamentales a los empleados públicos.

Quienes sostenían la tesis contraria, en tanto, postulaban que de la afirmación que los funcionarios públicos son titulares de derechos fundamentales no se colige necesariamente la procedencia de la acción de al ámbito público. En ese sentido, Valdivia postuló que no era un tema pacífico conferir competencia a los tribunales del trabajo para conocer y resolver asuntos de interés de la Administración. Además, advirtió que las consecuencias patrimoniales de estos remedios tutelares no están en sintonía con los derechos de los funcionarios públicos reconocidos por el Estatuto Administrativo, por lo que su acogimiento puede derivar en una serie de inconsistencias. 5 En otros términos, a juicio del autor, los resultados o efectos del acogimiento de la acción de tutela son incompatibles con el régimen de función pública.

En la misma vereda, Díaz se mostró contraria a que, con base en el argumento de la supuesta supletoriedad de la legislación laboral común, se extrajera la conclusión de que los tribunales del trabajo fuesen competentes para conocer cuestiones propias del ámbito público, señalando que las materias vinculadas a las cuestiones de competencia están reservadas a leyes orgánicas. A su juicio, resulta «inaceptable jurídicamente que el juez, laboral o no, se atribuya competencias en materias cuya definición, según el constituyente compete a leyes orgánicas constitucionales».56

\section{La Ley 21.280 y la opción por la laboralización}

Finalmente, la Ley 21.280 vino a dirimir este debate inclinándose por la aplicación de la acción de tutela al ámbito público. Para ello, interpreta el inciso primero del artículo i del Código del Trabajo aclarando que la acción es aplicable a todos los trabajadores, incluidos los de la Administración del Estado, centralizada y descentralizada, del Congreso Nacional, del Poder Judicial y de las empresas del Estado. Asimismo, declara expresamente que es aplicable a los trabajadores del Tribunal Constitucional, Justicia Electoral, Contraloría General de la República, Fuerzas Armadas, de Orden y Seguridad, Banco Central y a aquellos que sus leyes declaren como autónomos. ${ }^{57}$

"Valdivia, José Miguel, cit. (n. 9), pp. I26-127.

${ }^{56}$ Díaz, Cecilia, cit. (n. 42), pp. 83 y ss.

57 Artículo I de la Ley 2I.280, publicada en el Diario Oficial del 9 de noviembre de 2020. 
En cuanto al régimen indemnizatorio en caso de que la acción de tutela sea ejercida con ocasión del despido o cese de funciones, el artículo 2 número 2 de la ley dispuso que, de acogerse la acción de tutela, no procede el pago de la indemnización sustitutiva del aviso previo, así como la de ańos de servicio, favoreciendo de esa manera la tesis que se inclinaba por la falta de compatibilidad del régimen sancionatorio de la acción de tutela con los derechos de los funcionarios públicos regulados en el Estatuto Administrativo. De esta manera, en caso de acogerse la acción, la indemnización que resultará procedente es la especial de tutela que va de seis a once remuneraciones.

Para el caso del despido discriminatorio grave — calificación que realiza el juez de la causa a solicitud de parte—, la ley entrega al trabajador la opción de elegir entre el pago de la indemnización correspondiente o la reincorporación al cargo.

Sin perjuicio de que la Ley 2I.280 optó por otorgar competencia a los tribunales del trabajo para conocer acciones de tutela de derechos fundamentales incoadas por funcionarios públicos, a continuación, revisaremos los principales criterios jurisprudenciales que marcaron este interesante debate.

\section{LOS ZIGZAGUEOS DE LA JURISPRUDENCIA JUDICIAL EN TORNO}

\section{A LA APLICACIÓN DE LA ACCIÓN DE TUTELA DE DERECHOS} FUNDAMENTALES A LOS TRABAJADORES PÚBLICOS

El camino que han debido recorrer los trabajadores públicos para obtener una tutela judicial efectiva ante lesiones de sus derechos fundamentales durante la vigencia de la relación laboral o con ocasión de su término no ha sido fácil. Pronunciamientos disimiles de 1 os tribunales de justicia han marcado la tónica de este andar, los que han fluctuado entre la tesis del divorcio total de regímenes y la tesis que se abre a la aplicación de instituciones del derecho del trabajo, dadas las falencias o insuficiencias de la norma estatutaria.

\section{Primera fase: la declaración de incompetencia de los tribunales del trabajo}

En el comienzo de esta historia fueron los propios tribunales del trabajo quienes declararon su incompetencia para conocer de acciones de tutela de derechos fundamentales incoadas por trabajadores públicos, fundada principalmente en que los empleados públicos se rigen por el Estatuto Administrativo y/o estatutos especiales, que excluyen la aplicación de las normas del Código del Trabajo, entre ellas, la acción de tutela de derechos fundamentales. 
En este sentido se pronunció el juez titular del Juzgado de Letras del Trabajo de Coyhaique, don Oscar Barría Alvarado, al no dar curso a una denuncia de tutela de derechos fundamentales por dirigirse en contra de la Dirección General de Aeronáutica Civil, servicio público descentralizado que se rige por una normativa especial. En razón de ello, el magistrado, de conformidad con lo dispuesto en los artículos I y 420 del Código del Trabajo, Ley 16.752, que fija organización y funciones y establece disposiciones generales para la Dirección General de Aeronáutica Civil, y la Ley I8.834, sobre Estatuto Administrativo, resolvió no dar curso a la denuncia. $^{58}$

Del mismo modo, la jueza titular del Primer Juzgado de Letras del Trabajo de Santiago, doña Ximena Rivera Salinas, ante una acción de tutela ejercida por extrabajadores del Consejo Nacional de la Cultura y las Artes, declaró de oficio su incompetencia, toda vez que de acuerdo con el artículo 26 de la Ley Orgánica del Consejo Nacional de la Cultura y las Artes su personal está afecto a las disposiciones del Estatuto Administrativo de los funcionarios públicos, por lo que los denunciantes, en su calidad de exfuncionarios públicos, quedan excluidos de la aplicación de las disposiciones del Código del Trabajo, dentro de las cuales se encuentra el procedimiento de tutela laboral. 59

La jueza titular del Primer Juzgado de Letras del Trabajo de Santiago, doña María Morandé Dattwyler, en tanto, conociendo de una acción de tutela dirigida contra el Ministerio de Educación, declaró su incompetencia de oficio, ya que al estar los denunciantes regidos por un estatuto especial (leyes I8.834 y I8.056), se hacen inaplicables las normas contenidas en el Código del Trabajo; el tribunal competente es el Juzgado Civil de Santiago que corresponda. ${ }^{60}$

Ańadiendo un nuevo elemento a la tesis de la incompetencia, la jueza titular del Juzgado de Letras del Trabajo de Temuco, doña Marta Álvarez Basáez, sostuvo que de la redacción contenida en la norma que fija la competencia de los tribunales del trabajo (artículo 420 del Código del Trabajo)

${ }^{8}$ Resolución del Juzgado de Letras del Trabajo de Coyhaique del 22 de diciembre de 2009, causa RIT T-I-20I9, caratulada «Pinto con Dirección General de Aeronáutica Civil».

59 Resolución del Primer Juzgado de Letras del Trabajo de Santiago del I4 de junio de 20IO, causa RIT T-I3-20IO, caratulada «Riquelme con Consejo Nacional de la Cultura y las Artes».

${ }^{60}$ Resolución del Primer Juzgado de Letras del Trabajo de Santiago del II de agosto de 20Io, causa RIT T-22I-20Io, caratulada «Campos con Ministerio de Educación». Confirmada por la Corte de Apelaciones de Santiago en causa rol II55-20io. 
se desprende que no se incluye dentro de su catálogo de materias el conocimiento de conflictos existentes entre funcionarios públicos y el Estado, remitiéndose exclusivamente a los conflictos generados entre empleadores y trabajadores del sector privado. ${ }^{61}$

Sin pretender agotar los pronunciamientos judiciales que han defendido la tesis de la incompetencia, los ejemplos que aquí se dan muestran la tesis del divorcio de regímenes al negarse la competencia de los tribunales del trabajo para conocer de acciones de tutela de derechos fundamentales ejercidas por trabajadores públicos, fundada en que los denunciantes, en tanto exfuncionarios públicos, estaban sujetos a un estatuto especial, lo cual excluye la aplicación de las normas del Código del Trabajo.

\section{Segunda fase: el vuelco de las Cortes de Apelaciones}

Fueron las respectivas Cortes de Apelaciones las que al conocer de los recursos de apelación interpuestos en contra de las resoluciones que declararon la incompetencia revirtieron esta situación, aplicando supletoriamente el Código del Trabajo al tenor de lo dispuesto en el inciso tercero de su artículo I. El argumento fue sencillo: la acción de tutela no se encuentra regulada en ninguno de los estatutos que rigen al personal del Estado, por lo que, al tratarse de la protección de derechos fundamentales de que son titulares todos los ciudadanos y que el Estado debe respetar en virtud de la Constitución, no existe incompatibilidad alguna para aplicar la acción regulada en el Código del Trabajo.

En efecto, la Corte de Apelaciones de Santiago revocó la resolución dictada por el Primer Juzgado de Letras del Trabajo de Santiago, en la causa RIT T-I39-20Io, declarando la competencia del referido tribunal para conocer de la acción de tutela de derechos fundamentales interpuesta por exfuncionarios del Consejo Nacional de la Cultura y las Artes, señalando que en virtud del mandato de inexcusabilidad de los artículos 76 de la Constitución Política y ıo del Código Orgánico de Tribunales, le incumbe decidir, en sentencia de fondo, ante qué tipo de relación de trabajo se encuentra. ${ }^{62}$

Asimismo, la Corte de Apelaciones de Coyhaique revocó la resolución pronunciada en la causa RIT T-I-2009 del Juzgado de Letras del Trabajo

${ }^{6 r}$ Resolución del Juzgado de Letras del Trabajo de Temuco del 13 de septiembre de 20I0, causa RIT T-ı9-20IO, caratulada «Gajardo con Intendencia Regional de la Araucanía». Confirmada por la Corte de Apelaciones de Temuco el 23 de noviembre de 20Io, en la causa rol I42-20IO.

${ }_{62}$ Sentencia de la Corte de Apelaciones de Santiago del 4 de octubre de 20Io, en causa rol 850-2010, caratulada «Riquelme con Consejo Nacional de la Cultura y las Artes». 
de dicha ciudad, al estimar que la norma que habilita al tribunal para conocer de la denuncia de tutela laboral está contemplada en el inciso tercero del artículo i del Código del Trabajo, en cuanto esta hace la excepción respecto de los trabajadores del Estado, disponiendo que se sujetarán al Código del Trabajo «en los aspectos y materias no regulados en sus respectivos estatutos, siempre que ellas no fueren contrarias a estos últimos». ${ }^{63}$

La Corte de Apelaciones de Valparaíso, en tanto, conociendo de un recurso de nulidad interpuesto en contra de la sentencia definitiva pronunciada por el Juzgado de Letras del Trabajo de Valparaíso, que rechazó la demanda de tutela deducida en contra del Consejo Nacional de la Cultura y las Artes al acoger la excepción de falta de legitimación activa, estimó que se infringió el artículo i del Código del Trabajo, en relación con el artículo 485 del mismo cuerpo legal. Lo anterior lo sostuvo toda vez que, en la especie, el Estatuto Administrativo no contempla una acción especial cuyo objeto sea la protección de los derechos fundamentales, razón por la cual resulta aplicable la acción de tutela de derechos fundamentales regulada en el Código del Trabajo, siendo totalmente compatible con su estatuto especial, ya que, en definitiva, se busca cautelar derechos fundamentales que se reconocen a todas las personas sin distinción. ${ }^{64}$

A partir de las resoluciones citadas, se comienza a construir la tesis de la supletoriedad de las reglas del Código del Trabajo cuando la normativa estatutaria no regula una determinada materia, en este caso, una acción judicial destinada a tutelar los derechos fundamentales de los trabajadores dependientes, acción que está en completa armonía con el estatuto especial, ya que lo que busca es cautelar derechos fundamentales que se reconocen a todas las personas sin distinción.

\section{Tercera fase: primer criterio en unificación de jurisprudencia}

Pese al vuelco jurisprudencial que se produjo en los inicios del debate en torno a la competencia de los tribunales del trabajo, el panorama judicial para los empleados públicos ha sido incierto. Si bien se fue afianzando la tesis de la competencia dada la aplicación supletoria del Código del Trabajo, dicha línea jurisprudencial no fue uniforme. Como en muchas otras materias, la tutela judicial efectiva de los derechos fundamentales de los trabajadores públicos quedó supeditada al criterio del juez de turno, de su respectiva Corte de Apelaciones - y de los ministros que estén integrando

${ }_{63}$ Sentencia de la Corte de Apelaciones de Coyhaique de 4 de febrero de 20Io, en causa rol I-20ro, caratulada «Pinto con Dirección General de Aeronáutica Civil».

${ }^{64}$ Sentencia de la Corte de Apelaciones de Valparaíso del i2 de septiembre de 20I2, en causa rol 334-20II, caratulada «Torrealba con Consejo Nacional de la Cultura y las Artes». 
la sala respectiva $-y$, finalmente, del criterio que predomine en la Cuarta Sala de la Corte de Suprema. ${ }^{65}$

En este escenario de incertidumbre judicial: ¿cuál fue la postura de la Corte Suprema? En el comienzo de esta larga historia la Corte Suprema se plegó a la interpretación formalista y a la tesis de separación total de regímenes del mundo público y privado (incomunicación entre el régimen estatutario y el régimen privado del Código del Trabajo), uniformando la jurisprudencia en el sentido que los tribunales del trabajo carecen de competencia para conocer acciones de tutela de derechos fundamentales incoadas por trabajadores públicos. En efecto, en voto unánime, la Cuarta Sala de la Corte Suprema sostuvo en este primer recurso de unificación que el cuerpo normativo que rige a los funcionarios públicos —el Estatuto Administrativo-, tiene su propia regulación en torno a las calidades funcionarias que pueden formar parte de una dotación institucional y en cuanto a las causales de expiración en los cargos de contratados, con lo cual se excluye el imperio del derecho laboral común, al tenor de lo dispuesto en los artículos I y ir del Estatuto Administrativo, así como en los incisos segundo y tercero del artículo I del Código del Trabajo. Junto con ello, la Corte argumentó que, del tenor del artículo 485, este solo resulta aplicable a la vinculación surgida en los términos de los artículos 7 y 8 del Código del Trabajo, y, en caso alguno, a la relación estatutaria a la que se someten los funcionarios públicos a contrata. ${ }^{66}$

Consideramos que fue poco acertado este primer criterio de unificación sustentado por la Corte Suprema, ya que en ninguno de los artículos del Título VI del Estatuto Administrativo, relativo a la cesación de funciones, se contempla alguna norma cuyo objeto sea otorgar a los trabajadores públicos la posibilidad de ejercer una acción judicial para reclamar

6s Solo a modo referencial, la propia Corte de Apelaciones de Valparaíso, en causa rol 350-20iI, conociendo de un recurso de nulidad en contra de la sentencia definitiva que acogió una acción de tutela por vulneración de garantías fundamentales en contra del Gobierno Regional de Valparaíso, estableció un criterio totalmente distinto al que había sustentado hace pocos días atrás en la causa rol 334-20II, al sostener que al ser aplicable a los funcionarios denunciantes el Estatuto Administrativo, no tiene aplicación el Código del Trabajo, y, en consecuencia, tampoco el procedimiento tutela laboral, ya que, además, de las disposiciones de los artículos 486 y 420 del Código del Trabajo se desprende que no está dentro de la esfera de competencia de los tribunales del trabajo los conflictos que se susciten entre los funcionarios públicos y el Estado. En ambas causas el conocimiento de los recursos correspondió a salas y ministros distintos, lo que explica el cambio abrupto de criterio en tan solo nueve días.

${ }^{66}$ Corte Suprema, recurso de unificación de jurisprudencia causa rol 1972-20II, caratulada «Castillo con Intendencia Regional de la Araucanía». 
que, con ocasión del cese de sus funciones, se han lesionado sus derechos fundamentales: derecho a la vida e integridad física o psíquica, libertad de expresión, derecho a no ser discriminado, entre otros. Que estén reguladas las causales de cese de funciones - renuncia, remoción de los cargos de exclusiva confianza, obtención de jubilación o renta vitalicia, declaración de vacancia, cumplimiento del plazo, supresión del empleo por procesos de reestructuración o fusión - no significa que se entreguen los suficientes resguardos y herramientas jurídicas para recurrir ante los tribunales de justicia frente a situaciones en que la apariencia legal del cese de funciones encubre alguna lesión de un derecho fundamental. No hay regulación alguna de los derechos fundamentales de los trabajadores públicos, ni mucho menos el estatuto especial de los funcionarios públicos entrega una acción judicial destinada a tutelar tales derechos en el evento de que sean lesionados por el Estado-empleador en el ejercicio de sus facultades.

Dicho lo anterior, podemos sostener que la primera tesis sustentada por la Corte Suprema era ligera, totalmente artificial y sin sustento normativo ya que, como hemos dicho, el Estatuto Administrativo no contiene ninguna norma relativa a la tutela judicial de los derechos fundamentales de los empleados públicos, ni durante la vigencia de la relación laboral ni con ocasión del cese de funciones, por lo que estamos ante una verdadera omisión de regulación que hace aplicable el Código del Trabajo, de acuerdo a lo dispuesto en el inciso tercero de su artículo I.

\section{Cuarta fase: la nueva sala laboral de la Corte Suprema $y$ la tesis a favor de la competencia}

Afortunadamente, el criterio de unificación que negaba la competencia de los tribunales del trabajo no duró mucho tiempo. A partir de la sentencia rol I0.972-20I3 el criterio fue el opuesto: la plena competencia de los tribunales del trabajo para conocer acciones de tutela de derechos fundamentales — vigente la relación laboral o con ocasión de su término- iniciadas por trabajadores públicos. ${ }^{67}$ Los fundamentos entregados

${ }^{67}$ El camino hacia el reconocimiento de la competencia de los Juzgados del Trabajo para conocer de acciones de tutela de derechos fundamentales ejercidas por funcionarios públicos estuvo marcado por las siguientes sentencias de unificación de la Corte Suprema: rol 938I-20I2, caratulada "Rosas con Servicio de Salud Sur», donde si bien se reitera el criterio de incompetencia, se dan los argumentos para la tesis contraria en el voto en contra del ministro Lamberto Cisternas; rol 5967-2013, caratulada «Andrade con Ministerio Público», con votos en contra sustentando la tesis de la competencia de la ministra Ana Gloria Chevesich y del ministro Ricardo Blanco; y, finalmente, la causa rol I0.972-20I3, 
para justificar este cambio de criterio son variados y los revisaremos brevemente.

El voto de mayoría parte haciendo un análisis del procedimiento de tutela laboral introducido por la Ley 20.087 , poniendo en el centro la función limitadora que cumplen los derechos fundamentales respecto de los poderes empresariales. Citando el mensaje presidencial que acompañó al proyecto de ley, la Corte enfatizó que, para hablar de una efectiva vigencia de los derechos fundamentales en el seno de la relación laboral, no basta con su reconocimiento material, sino que, ante todo, deben reconocerse mecanismos de tutela jurisdiccional eficaces e idóneos. Luego, para el caso de los trabajadores públicos, la Corte sostuvo que, si bien el inciso segundo del artículo i del Código del Trabajo los excluye de su ámbito de aplicación, en el inciso tercero de la referida norma se prevé la posibilidad de que «a los trabajadores de las entidades señaladas en el inciso precedente les sean aplicables las normas del Código del Trabajo, si concurren los siguientes requisitos copulativos, a saber, que se trate de materias o aspectos no regulados en sus respectivos estatutos y, en seguida, que ellas no fueren contrarias a estos últimos» (considerando undécimo). Respecto del primero de los requisitos, la Corte constató correctamente que el Estatuto Administrativo no contiene normas que regulen un procedimiento jurisdiccional especial para conocer y resolver denuncias de vulneración de derechos fundamentales que afecten a los funcionarios en el ámbito de la relación de trabajo. No entra dentro de la categoría de procedimiento jurisdiccional especial el procedimiento de reclamo que consagra el artículo i6o del Estatuto Administrativo, ya que es un recurso administrativo del que conoce la Contraloría General de la República por vicios de legalidad que pudieren afectar los derechos conferidos a los funcionarios en dicho estatuto. A raíz de lo anterior, la Corte concluyó "que se cumple el primer requisito previsto en la norma, cual es, que exista un vacío legal en el estatuto especial, respecto de una materia o aspecto que sí se encuentra regulado en el Código del Trabajo, como es el procedimiento de tutela laboral» (considerando duodécimo).

En lo tocante al segundo requisito, la Corte sostuvo que no existe ningún capítulo o norma en el Estatuto Administrativo que pugne con la protección de los derechos fundamentales de los funcionarios públicos, añadiendo que «no se advierte cómo normas protectoras de dichos derechos podrían ser incompatibles con lo dispuesto en el estatuto especial que rige a 
aquellos funcionarios, toda vez que es dable asumir que el Estado, en cuanto empleador, ha de cumplir con el deber de asegurar el pleno respeto de los derechos fundamentales de que también son titulares los funcionarios que trabajan en la Administración del Estado» (considerando decimotercero).

Dada la entidad y naturaleza de los derechos que se pretenden tutelar a través de esta acción, la Corte Suprema, en el voto de mayoría, afirmó que «no existe una razón jurídica valedera para excluir de su aplicación a toda una categoría de trabajadores, como son los funcionarios públicos», ya que en un contexto de trabajo dependiente y subordinado, «la vigencia real de los derechos fundamentales puede verse afectada a consecuencia del ejercicio de las potestades del Estado empleador» (considerando decimoquinto). Sobre la base de los argumentos expuestos, la Corte procedió a unificar la jurisprudencia en el sentido en que los tribunales del trabajo son competentes para conocer de acciones ejercidas por trabajadores públicos para denunciar la vulneración de derechos fundamentales en el ámbito del trabajo.

La doctrina contenida en el caso en estudio - conocida como la doctrina Bussenius—, marcó un precedente importante, especialmente porque derribó la dicotomía trabajador/funcionario público al sostener que el Código del Trabajo incluye dentro del concepto de trabajadores a los funcionarios públicos, toda vez que, de acuerdo con el tenor literal del artículo I inciso tercero, la expresión trabajadores se utiliza para referirse a los funcionarios públicos: «los trabajadores de las entidades señaladas en el inciso precedente». ${ }^{68}$

Este duro y largo camino que han debido recorrer los trabajadores del Estado para obtener esta tutela no terminó aquí. Al consolidarse la tesis de la competencia de los tribunales del trabajo en sede de unificación de jurisprudencia, ${ }^{69}$ los defensores del Estado-empleador (incluidos los gobiernos locales) debían buscar una nueva estrategia, y esta fue el requerimiento de inaplicabilidad por inconstitucionalidad ante el Tribunal Constitucional (TC).

${ }^{68}$ Para Díaz, la doctrina contenida en el caso Bussenius es errada. A su juicio, la utilización opcional de los términos trabajadores o funcionarios públicos supone que dichos funcionarios se encuentren vinculados a un contrato de trabajo, toda vez que de la interpretación armónica de los artículos 485, 486 y 489 del Código del Trabajo se desprende como requisito para la aplicación de la acción de tutela que estemos ante trabajadores dependientes regidos por el Código del Trabajo y no por estatutos especiales. DíAz, cit. (n. 42), p. 90.

${ }_{69}$ Entre otras, sentencias dictadas por la Corte Suprema rol I0972-20I3 del 30 de abril de 20I4; rol 57I6-20I5 del I de diciembre de 20I5; rol I9515-20I5 del 20 abril de 20I6; rol I8.740-20I8 del 25 de abril de 20I9; y rol 22.879-2020 del I5 de mayo de 2020 . 


\section{Quinta fase: la intervención del Tribunal Constitucional}

El debate judicial en torno a la aplicación de la acción de tutela laboral a los trabajadores públicos no terminó en sede de unificación de jurisprudencia. En una gestión judicial pendiente, donde se demandó por vulneración de derechos fundamentales con ocasión del despido a la Municipalidad de San Miguel, la defensa del denunciado recurrió ante el TC, como se verá a continuación.

Una extrabajadora de la Municipalidad de San Miguel dedujo denuncia de tutela de derechos fundamentales con ocasión del despido, fundada en que su desvinculación obedeció a razones políticas, dada la llegada de un nuevo alcalde a la comuna. La Ilustre Municipalidad de San Miguel, en tanto, siendo notificada, no contestó la denuncia dentro de plazo legal.

Realizadas las audiencias preparatoria y de juicio, la jueza del trabajo que conoció la causa concluyó que se encontraba acreditado de manera suficiente el despido discriminatorio alegado por la trabajadora, toda vez que la no renovación de su contrata no tuvo justificación y desatendió el decreto anterior donde se disponía su renovación por toda la anualidad siguiente. A ello se agregaron los indicios aportados por la actora en torno a demostrar que la posición política de izquierda que ella tenía y la afinidad con el exalcalde de la comuna (que era del Partido Socialista), era de público conocimiento, incluido el actual alcalde, que anteriormente era concejal de la comuna. Se añadió a estos indicios la línea política del exconcejal y actual alcalde, la que era completamente opuesta a la de la actora y alcalde saliente (Partido Renovación Nacional).

En razón de lo anterior, la sentencia dio lugar a la denuncia de tutela de derechos fundamentales con ocasión del despido, declarando que la Ilustre Municipalidad de San Miguel vulneró el derecho fundamental a la no discriminación por opinión política, siendo condenada al pago de la indemnización especial de tutela por ocho meses de remuneración, junto con la indemnización por lucro cesante en razón de haber sido desvinculada sin respetar la renovación que se había dispuesto previamente por toda la anualidad siguiente. ${ }^{70}$

En contra del fallo, la Municipalidad de San Miguel dedujo recurso de nulidad, invocando como causal principal la infracción de ley, al haberse aplicado el procedimiento de tutela laboral que contempla el Código del Trabajo respecto de una funcionaria municipal regida por un estatuto especial (Ley I8.883, Estatuto Administrativo para Funcionarios Munici-

$7^{\circ}$ Sentencia del Juzgado de Letras del Trabajo de San Miguel del I de junio de 20I7, en causa RIT T-I7-20I7, caratulada "Navarrete con Ilustre Municipalidad de San Miguel». 
pales). La Corte de Apelaciones de San Miguel, conociendo el recurso interpuesto por la Municipalidad, resolvió rechazarlo, argumentando que, si bien es cierto que la trabajadora se encontraba sometida a un estatuto especial, este no contempla un procedimiento judicial para el caso de vulneración de derechos fundamentales con ocasión del término de la relación de trabajo, de manera que resulta aplicable la acción de tutela regulada en los artículos 485 y siguientes del Código del Trabajo. ${ }^{71}$

La Municipalidad de San Miguel, insistiendo en su tesis, interpuso contra la sentencia de la Corte de Apelaciones de San Miguel un recurso de unificación de jurisprudencia para ser conocido por la Corte Suprema, fundado en que existían distintas interpretaciones emanadas de tribunales superiores de justicia en torno a si los tribunales del trabajo tienen o no competencia para conocer de acciones de tutela de derechos fundamentales interpuestas por trabajadores públicos a contrata. Como la línea jurisprudencial dominante en sede de unificación de jurisprudencia era a favor de la competencia de los Juzgados de Letras del Trabajo, la Municipalidad de San Miguel interpuso un requerimiento de inaplicabilidad por inconstitucionalidad respecto de los artículos I inciso tercero y 485 del Código del Trabajo.

Luego de una larga tramitación (el requerimiento ingresó el 8 de septiembre de 2017 y la sentencia se dictó el 6 de diciembre de 2018), el TC decidió en voto de mayoría acoger el requerimiento de inaplicabilidad, señalando, en síntesis, que la supletoriedad consagrada en el inciso tercero del artículo I del Código del Trabajo, "configura una fórmula dúctil e imprecisa, que se presta para aplicaciones extensivas, al punto de llegar a ampliar la intervención de los tribunales del trabajo más allá de su natural órbita competencial», estimando que este resultado - la competencia de los tribunales del trabajo en cuestiones estatutarias de derecho públicovulnera los artículos 6, 7 y 38 de la Constitución Política, ya que de ello se deriva una competencia que ninguna ley les ha conferido. ${ }^{72}$

En base a lo anterior, el TC declaró inaplicables los artículos I inciso

${ }^{71}$ Sentencia dictada por la Corte de Apelaciones de San Miguel del 2 de agosto de 20I7, en causa rol 236-2017, caratulada «Arriaza con Ilustre Municipalidad de San Miguel». El caratulado de la causa cambió, ya que tomó el apellido de la abogada de la denunciante.

${ }^{72}$ Sentencia del Tribunal Constitucional, en causa rol 3853-17 del 6 de diciembre de 20I8. Concordando con la doctrina del TC, Díaz sostiene que no es posible inferir reglas de competencia a partir del carácter supletorio de la legislación laboral, ya que, de lo contrario, se estaría infringiendo el principio de legalidad que exige que las potestades de los órganos públicos sean definidas por ley. Díaz, cit. (n. 42), pp. 9I y ss. 
tercero y 485 del Código del Trabajo, al estimar que estos vulneran los artículos 6, 7 y 8 de la Constitución Política, especialmente porque a partir del supuesto carácter supletorio del Código del Trabajo se deriva una competencia para los Juzgados de Letras del Trabajo que ninguna ley le ha conferido de forma expresa.

El problema que hay detrás de esta argumentación es que el TC no comprende los alcances del inciso tercero del artículo I del Código del Trabajo, soslayando su aplicación sobre la base de la inexistencia de una ley que confiera competencia a los Juzgados del Trabajo para conocer de acciones de tutela de derechos fundamentales ejercidas por trabajadores del Estado. Sin embargo, es el propio Código del Trabajo, una ley de la República, el que expresamente confiere esta competencia, ya que, de acuerdo con su artículo I inciso tercero, es legislación común aplicable a todo tipo de trabajo dependiente, ${ }^{73}$ incluido el trabajo que se presta al Estado, teniendo en tal caso carácter de legislación supletoria. Recordemos que esta norma consagra una contraexcepción, estableciendo que los trabajadores del Estado, en principio excluidos del ámbito de aplicación de las normas del Código del Trabajo, se sujetarán de todos modos al mismo, siempre que se reúnan las siguientes exigencias: que haya una omisión de regulación o vacío legal, es decir, el Código del Trabajo y sus leyes complementarias podrían ser aplicables respecto de materias o aspectos no regulados en los estatutos de los trabajadores del sector público, y que exista una compatibilidad de regímenes, es decir, que las materias que resulten aplicables en razón del vacío legal existente en sus estatutos, no sean contrarias a estos últimos.

Tal como indica el TC, el origen de esta disposición se encuentra en el Decreto Ley 2.200 de 1978, pero, por razones obvias, para efectos de analizar sus antecedentes históricos, debemos remitirnos a la tramitación legislativa de la Ley 18.620, que aprobó el nuevo Código del Trabajo.

Resulta que en las discusiones de la Ley 18.620 se tuvieron a la vista las dos posiciones doctrinarias existentes en esa época respecto de la aplicación supletoria del Código del Trabajo al sector público. Así, se advirtió que la mayoría de los tratadistas estimaban que, atendido que el funcionario público es objeto de un nombramiento y que su incorporación a la Administración no es producto de un negocio jurídico, no le debieran ser aplicables, ni aun con carácter subsidiario, las normas laborales del sector privado. Sin embargo, otros tratadistas pensaban que, considerando el carácter expansivo del derecho del trabajo y la circunstancia de que tanto

${ }^{73}$ Marín Vallejo, Urbano, cit. (n. 4), p. 240. 
el servidor público como el dependiente privado ejecutan una prestación de servicios remunerada, sería atendible tal aplicación subsidiaria. Frente a estas dos posturas, el proyecto de ley se inclinó por conferirle al Código del Trabajo el carácter de legislación supletoria del sector público en aquellos aspectos o materias que no fueren contrarios o incompatibles con el estatuto que los rija. ${ }^{74}$ Este dato histórico no se aviene con las conclusiones que extrae el voto de mayoría del TC en torno a que la redacción de la norma en referencia obedecería a una supuesta indefinición sobre el régimen al que debían someterse los empleados públicos, lo que a su juicio explicaría la «maleabilidad con que fue diseñada la supletoriedad de marras, en el DL 2.200, de 1978, y luego en la Ley I8.620 de 1987».75

Pues bien, lo cierto es que en aquella época estaban presentes estas dos visiones, primando en definitiva aquella que confiere al Código del Trabajo el carácter de derecho común regulatorio de todo trabajo dependiente, pues sus normas se aplican al personal que presta servicios dependientes al Estado en todos los aspectos no regulados en sus respectivos estatutos.

No existiendo duda de que estamos ante una norma que estatuye la supletoriedad del Código del Trabajo en el régimen de función pública, sus alcances son respecto de todos aquellos aspectos o materias que no fueren contrarios o incompatibles con el estatuto que los rija. En otros términos, la supletoriedad que consagra el inciso tercero del artículo i del Código del Trabajo es de carácter amplia, por lo que su objetivo, tal como ha indicado la Corte Suprema, ${ }^{76}$ no es complementar aspectos secundarios

${ }^{74}$ En el informe de la Secretaría de Legislación expresamente se indica: «El sentido de esta enmienda es el de enfatizar la generalidad del campo de aplicación del Código del Trabajo, manteniendo su carácter expansivo, en cuanto su normativa se aplicará también supletoriamente a los funcionarios públicos o trabajadores de empresas afectas al sector público. Desde otro punto de vista, cabe advertir que podría entenderse que media en la especie una innovación que tiene efectos jurídicos, en cuanto se dispone que la legislación laboral será la normativa supletoria aplicable a los funcionarios públicos en aquellos aspectos o materias que no fueren contrarios o incompatibles con el estatuto que los rija». Biblioteca del Congreso Nacional de Chile, Historia de la Ley i8.620 Código del Trabajo, Informe de la Secretaría de Legislación, pp. 519-520.

${ }_{75}$ Considerandos quinto y sexto de la sentencia de inaplicabilidad, rol 3853-17-INA.

${ }^{76}$ A propósito del debate de la aplicación de la acción por despido indirecto (regulada en el artículo I7I del Código del Trabajo) al personal sujeto al Estatuto Docente, la Corte Suprema, en recurso de unificación de jurisprudencia, rol 94I-20I8, caratulado "Rivas con Corporación Municipal de Valparaíso para el Desarrollo Social», sostuvo: "La aplicación supletoria de un cuerpo normativo, en la especie el Código del Trabajo, no debe tener por objeto complementar aspectos secundarios o de mera reglamentación, pero sí corresponde darle aplicación frente a una situación sustantiva importante, una verdadera institución jurídico-laboral, regulada en dicho código». 
o de mera reglamentación, sino que, por el contrario, la complementación se refiere a cuestiones sustantivas, de importancia, integrando los vacíos del régimen estatutario con instituciones jurídico-laborales reguladas en el Código del Trabajo.

En relación con la materia comentada - acción de tutela de derechos fundamentales—, ni el Estatuto Administrativo general (Ley 18.884), ni el Estatuto Administrativo para Funcionarios Municipales (Ley 18.883), ni los diversos estatutos especiales que regulan a determinados trabajadores públicos, contienen una regulación específica que consagre un mecanismo de tutela judicial ante lesiones de derechos fundamentales de los trabajadores por parte de la Administración, sea durante la vigencia de la relación laboral o con ocasión de su término. En consecuencia, existe un vacío legal en la materia que permite aplicar las disposiciones sobre la acción de tutela de derechos fundamentales contenida en los artículos 485 y siguientes del Código del Trabajo, normativa que es perfectamente compatible con sus estatutos especiales, ya que se trata de la protección de derechos fundamentales de los cuales son titulares todos los ciudadanos, entre ellos los trabajadores públicos, y que el Estado debe respetar por mandato constitucional. En tal sentido, nadie podría sostener que, por el hecho de prestar servicios para el Estado, no son trasladables al ámbito de dicha relación de trabajo, los derechos que detenta toda persona por el hecho de ser tal. ${ }^{77}$

Ahora, el criterio reflejado en el voto de mayoría del $\mathrm{TC}^{78}$ no varió la tesis de la Corte Suprema en torno a la competencia de los tribunales del trabajo, ni para causas distintas que han sido falladas después de la senten-

77 Hay quienes sostienen que, atendida la especial relación de sujeción en el ámbito del empleo público, los derechos fundamentales de los funcionarios podrían ser restringidos o, a lo menos, establecer un tratamiento diferenciado. En ese sentido, DíAz, cit. (n. 42), p. 3 I.

${ }^{78}$ El voto de mayoría fue suscrito por los ministros señores Iván Aróstica Maldonado, Juan José Romero Guzmán, María Luisa Brahm Barril, Cristian Letelier Aguilar y José Ignacio Vásquez Márquez. Se consignó el voto en contra de los ministros Marisol Peña Torres, Gonzalo García Pino, Domingo Hernández Emparanza y Nelson Pozo Silva. Luego de esta primera sentencia, el TC ha mantenido la tesis de la incompetencia en innumerables requerimientos de inaplicabilidad que se han deducido. Entre otros, en causas roles 7584-19, 6892-2019, 7073-2019, 7289-2019, 7892-2019 y 8308-2020. Solo hemos detectado una inaplicabilidad rechazada, en causa rol 6752-2019, a raíz de haberse producido un empate de votos, por lo que, al no haberse alcanzado la mayoría constitucional necesaria para acoger un requerimiento, de conformidad con lo dispuesto por el artículo 93, inciso primero, 6, de la Constitución Política, se procedió a su rechazo. 
cia del TC,79 ni para la causa donde incidió este primer fallo de inaplicabilidad, según veremos a continuación.

\section{Conflicto Tribunal Constitucional versus Corte Suprema: la última palabra es la de los tribunales ordinarios}

La Confederación Nacional de Funcionarios Municipales de Chile dedujo acción constitucional de protección en contra del TC, denunciando como acto ilegal y arbitrario la sentencia pronunciada por dicho tribunal en la causa rol 3853-17 (el recurso de inaplicabilidad que hemos comentado). Como garantía constitucional conculcada, se invocó la igualdad ante la ley, prevista en el artículo I9 número 2 de la Constitución Política. La apuesta era arriesgada, ya que lo pretendido por los recurrentes era la revisión de la juridicidad de una sentencia del TC.

Si bien la acción de protección deducida fue rechazada por la Corte Suprema ${ }^{80}$ la sentencia tiene especial relevancia por dos razones. Primero, porque la Corte reafirmó un principio base del Estado de derecho: las actuaciones del TC no quedan al margen de la revisión que pueda hacer la jurisdicción. En razón de lo anterior, las actuaciones que este tribunal realice al margen de las atribuciones entregadas por la ley o la Constitución pueden ser controladas por la vía jurisdiccional mediante la acción constitucional de protección.

79 En efecto, después de la sentencia del TC la Corte Suprema ha mantenido su criterio en unificación a favor de la competencia de los tribunales del trabajo para conocer de acciones de tutela laboral incoadas por funcionarios públicos. Así, en sentencia de 25 de abril de 2019, en causa rol 18.740-2018, la Corte Suprema mantuvo el criterio a favor de la competencia, recordándonos que los derechos fundamentales protegidos a través de la acción de tutela laboral están reconocidos en la Constitución Política para toda persona, y que la carta fundamental tiene una jerarquía normativa superior a la normativa específica de la Administración Pública. Recientemente, el 5 de marzo de 2020, en causa rol 17.306I9, el máximo tribunal reiteró que los Juzgados del Trabajo son competentes para conocer de las demandas de tutela por vulneración de derechos fundamentales con ocasión del término de una contrata, sosteniendo que el artículo 420 letra a) del Código del Trabajo lo habilita para ello (regla de competencia general). En idéntico sentido puede verse la causa rol I8.566-I9, de la misma fecha.

${ }^{80}$ El fundamento central para el rechazo del recurso de protección fue que al estar pendiente la gestión judicial en la que recayó el fallo de inaplicabilidad (recurso de unificación en estado de acuerdo) no se hace necesaria una cautela urgente, estimando la Corte que son los integrantes que concurrieron a la vista de la causa del recurso de unificación los que deben determinar el alcance de la sentencia del TC rol 3853-17. Esto determinó, a juicio de la Corte, que no se cumplan las exigencias previstas para la procedencia del recurso de protección (considerando séptimo de la sentencia de protección de la Corte Suprema, causa rol 21.027-2019). 
En efecto, sin desconocer la autonomía e independencia del TC, los ministros de la Tercera Sala de la Corte Suprema sostuvieron que tal autonomía no puede implicar que sus actuaciones queden al margen de la revisión que puede hacer la jurisdicción conforme a los procedimientos consagrados en la propia Constitución Política. Ello, especialmente si el acto ilegal y/o arbitrario que se denuncia es que el TC ha actuado al margen de las atribuciones entregadas por la ley o la Constitución, es decir, fuera de la órbita de sus competencias.

En segundo lugar, la sentencia de protección, no obstante haber sido rechazada, tiene importancia para la gestión judicial que se encontraba pendiente, toda vez que en ella se señala que es el juez de fondo quien debe «verificar qué parte del pronunciamiento del Tribunal Constitucional es vinculante y obligatorio por emanar del ejercicio de las atribuciones que la Constitución y la ley le han entregado». En consecuencia, es el juez de la causa el que debe «determinar el alcance de la sentencia del Tribunal Constitucional rol 3853-I7-INA, para efectos de resolver el recurso de unificación de jurisprudencia que se encuentra pendiente ante ellos». En términos sencillos, será el juez del fondo el que tendrá la última palabra, debiendo verificar qué parte del pronunciamiento del TC es vinculante por emanar del ejercicio de las atribuciones que le confiere la ley y la Constitución. En este último punto, resultan relevantes también los argumentos entregados en el voto de prevención del ministro Muñoz, quien explica que la resolución de casos difíciles — cuando no hay norma expresa que resuelva el conflicto- admite distintas soluciones conforme sea la interpretación que realice el juez de fondo.

Pues bien, en la materia propuesta — determinar si los tribunales del trabajo son o no competentes para conocer acciones de tutela interpuestas por trabajadores públicos - existen dos vías interpretativas posibles: aceptar la competencia de los tribunales del trabajo, recurriendo para ello al carácter supletorio de la legislación laboral o a los principios del derecho del trabajo, entre ellos, el principio de protección de los trabajadores, versus aquella interpretación que confiere primacía al régimen estatutario de función pública. Existe entonces un problema de interpretación: el TC, al dictar la sentencia rol 3853-17, excedió su competencia, ya que, como indica el ministro Muñoz, en este caso el tribunal se constituyó en un revisor de la interpretación planteada, y resulta que su competencia se limita a determinar la constitucionalidad del precepto mismo y no si una determinada interpretación realizada por los tribunales ordinarios puede afectar disposiciones de la Constitución Política. En otras palabras, el TC no tiene competencia alguna para revisar la interpretación planteada por el juez de fondo. 
Volviendo a la cuestión de la importancia de la sentencia de protección en análisis, en la gestión judicial pendiente, los ministros que deben resolver el recurso de unificación de jurisprudencia son los que soberanamente deberán determinar los alcances de la sentencia de inaplicabilidad y, sobre todo, aquella parte que pueda resultar vinculante por emanar del ejercicio de las atribuciones que le confiere la ley y la Constitución. Entonces, como en el presente caso lo que hace el TC es revisar una de las tantas interpretaciones posibles en torno a la cuestión de la competencia de los tribunales del trabajo en relación con trabajadores del Estado — cuestión que excede las competencias que le confiere la propia Constitución Política-, los ministros de la Sala Laboral de la Corte Suprema podrán determinar que no les resulta vinculante la sentencia. Pero incluso sin llegar a ese punto pueden resolver la problemática reafirmando el criterio de la competencia en base a la interpretación de otras normas jurídicas, por ejemplo, acudiendo a las normas generales de competencia, ya que estamos ante un conflicto entre un empleador, que en este caso es el Estado, y sus trabajadores (artículo 420 letra a) del Código del Trabajo). De igual forma, se puede abordar esta problemática haciendo uso de los principios del derecho del trabajo, entre ellos, el principio protector y las reglas de interpretación propias de los derechos fundamentales, en este caso, el principio pro homine o pro civis, en virtud del cual se debe interpretar de la forma más amplia posible la protección de los derechos fundamentales de los trabajadores, tanto del sector público como del sector privado, por lo que, en caso de duda, la interpretación debe inclinarse hacia la fórmula más beneficiosa en tutela de los derechos fundamentales.

Pues bien, afortunadamente el largo camino judicial que debió recorrer la exfuncionaria de la Municipalidad de San Miguel tuvo frutos, toda vez que el is de diciembre de 2019 la Corte Suprema dictó sentencia rechazando el recurso de unificación de jurisprudencia que hubiera deducido la Municipalidad de San Miguel, no obstante existir un requerimiento de inaplicabilidad acogido por el TC. Analizaremos brevemente cuáles fueron los argumentos entregados por la Corte para rechazar el recurso de unificación.

$\mathrm{El}$ argumento central para resolver el rechazo del recurso estuvo vinculado con la naturaleza del recurso de unificación. La Corte explicó que se trata de un arbitrio que no opera bajo la lógica de verificar si hay un vicio o error de derecho, como sucede con los recursos anulatorios en general, sino que, constatada una dispersión jurisprudencial respecto de una determinada materia de derecho, el objeto del recurso es "proclamar el precedente válido para una determinada cuestión jurídica, en la medida 
que se corresponda con la disputa en la que recayó el juicio». Su objetivo, entonces, es corregir la dispersión jurisprudencial existente en los tribunales superiores de justicia.

Precisado el objetivo del recurso de unificación, la Corte nos recuerda que este procede respecto de la sentencia que se pronuncia sobre un recurso de nulidad laboral, por lo que es en esa sentencia - la de nulidad-, donde debe estar la posición dogmática sobre alguno de los puntos de derecho que fueron objeto del juicio.

Luego, con relación al recurso de inaplicabilidad por inconstitucionalidad, la Corte, analizando la jurisprudencia del propio TC, concluye que se trata de un arbitrio destinado a examinar la constitucionalidad de un precepto legal cuya aplicación a una gestión judicial pendiente puede resultar contraria a la Constitución. En razón de lo anterior, de acogerse la inaplicabilidad, el efecto que se produce es que el juez del fondo (el encargado de resolver la gestión judicial pendiente en que incidió la acción de inaplicabilidad) estará inhibido de aplicar la norma legal estimada inconstitucional.

Aclarados y delimitados los objetivos de los arbitrios procesales en juego, la Corte señala que para efectos de resolver el recurso de unificación, luego de la intervención del TC, hay una dificultad irredimible, toda vez que al excluir del universo los dos preceptos declarados inaplicables (artículo I inciso tercero y 485 del Código del Trabajo), está impedida de realizar el análisis jurídico-jurisprudencial que exige el recurso de unificación, ya que precisamente son los artículos que fueron objeto de interpretación y pronunciamiento expreso por parte de la Corte de Apelaciones en la sentencia de nulidad.

Explicaremos más en detalle esta conclusión. Si el pronunciamiento jurídico de la sentencia impugnada a través del recurso de unificación es que los tribunales del trabajo son competentes para conocer de acciones de tutela de derechos fundamentales deducidas por funcionarios públicos, en base a la interpretación de los artículos I inciso tercero y 485 del Código del Trabajo, la Corte Suprema, al estar inhibida de aplicar tales preceptos legales producto del pronunciamiento del TC, no podrá realizar el ejercicio comparativo que exige el recurso de unificación, ya que la decisión impugnada - la sentencia de nulidad-, quedó sin el fundamento normativo que la justifica — quedó desprovista de una exposición de motivos suficientemente eficaz. Como explica el fallo de unificación, «la decisión impugnada, en la práctica, en la materia de derecho en análisis, queda vacía de justificación doctrinal, y, por lo tanto, sin un pronunciamiento válido susceptible de comparación» (considerando decimotercero final). 
En otras palabras, «si el planteamiento jurídico que fundamenta el fallo impugnado es cercenado normativamente, como sucede en la especie, por medio de un acto institucional de expulsión normativa, resulta que esta Corte queda situada en una posición de imposibilidad práctica de considerar válido el pronunciamiento jurídico fundado en dichas normas para este caso particular». Como la decisión impugnada se sostiene en normas jurídicas que han sido declaradas inaplicables, la Corte está impedida de entrar al fondo del asunto, ya que al no haber ratio decidendi, no existe un pronunciamiento que sea posible contrastar con sentencias que hayan fallado en sentido contrario.

Para comprender de mejor forma por qué la Corte Suprema está impedida de hacer el ejercicio comparativo que exige el recurso de unificación, debemos recordar que no estamos ante un arbitrio procesal tradicional, ya que en esta sede no cabe «ni la enmienda de la decisión agraviante que contraría el derecho (efecto propio del recurso de apelación), ni el rol de nomofilaxis propio de la nulidad sustantiva (como sucede con la casación en el fondo y las causales que le son asimilables en el recurso de nulidad laboral)». Debido a esto, «la extensión del fallo de inaplicabilidad afecta el análisis que se debe realizar frente al presente arbitrio, pues al operar sobre la base de la constatación de posiciones jurisprudenciales contrarias, a fin de considerar su eventual unificación, no se puede soslayar el efecto negativo que provoca la decisión del Tribunal Constitucional en la fundamentación del fallo impugnado que se sustenta en preceptos declarados inaplicables» (considerando decimoquinto).

En definitiva, al quedar vaciada de contenido normativo la sentencia impugnada, por el efecto negativo o inhibitorio del fallo de inaplicabilidad, se hace imposible contrastarla con otras tesis jurídicas, y la Corte, dados los especiales objetivos del recurso de unificación, no puede corregir esa insuficiencia argumentativa de la sentencia. Es por ello que, posteriormente, en el considerando decimoctavo de la sentencia de unificación, la Corte concluye que el pronunciamiento que pueda emitir el TC cuando la gestión judicial pendiente está en sede de unificación de jurisprudencia carecerá de efectividad práctica, señalando que el planteamiento de una inaplicabilidad «en este estadio procesal aparece, desde una perspectiva de eficiencia, como impropio, o, por lo menos, inoportuno, procesalmente hablando».

Podemos ver que el rechazo del recurso de unificación se basa en un argumento procesal que se vincula con los alcances y objetivos del recurso, concluyendo que la sentencia de inaplicabilidad dictada por el TC llega tarde cuando la gestión judicial pendiente se encuentra en esta sede. 
Como explica Román Cordero, dada las particularidades del recurso de unificación de jurisprudencia —único en nuestro sistema recursivo-, este no puede ser considerado como gestión pendiente para los efectos del requerimiento de inaplicabilidad, toda vez que se trata de un arbitrio procesal que versa sobre un conflicto de legalidad abstracto. ${ }^{8 \mathrm{r}}$

En razón de lo anterior, la Corte Suprema nos recalca que la operatividad práctica de una sentencia favorable de una acción de inaplicabilidad — su efectividad—, no se garantiza con su mera dictación, ya que ello no depende del TC, sino que de diversas circunstancias que están fuera de su alcance. Como dijimos en un artículo anterior, ${ }^{82}$ la última palabra no la tiene el TC, ya que, sea por razones procesales o sustantivas, el tribunal a cargo de la gestión pendiente puede validar el resultado decisorio que se quería evitar por medio de la declaración de inaplicabilidad. En el caso en estudio ocurrió esto, ya que la Corte Suprema rechazó el recurso judicial que se encontraba pendiente (el de unificación), por defectos de índole procesal, puesto que, en razón de la finalidad específica de este arbitrio procesal —unificar la dispersión jurisprudencial—, la sentencia de inaplicabilidad llega tarde. En palabras del máximo tribunal, «no siempre una decisión de inaplicabilidad va a producir efectos prácticos en el proceso que pretende afectar, por lo que es posible la convivencia de decisiones del Tribunal Constitucional que no producen un efecto práctico en el terreno concreto, lo cual, en caso alguno significa desconsiderarlas, sino que consolida la idea de que su eficiencia requiere la existencia de un ámbito donde procesalmente sea posible su aplicación material» (considerando vigésimo). En ese contexto, a juicio de la Corte, «el recurso de unificación es uno de los casos en que la sentencia de inaplicabilidad concedida carece de eficacia en el caso concreto en que se pronuncia, desde que, conforme se explicó anteriormente, no contempla la posibilidad de dictamen sobre el fondo del asunto pendiente, lo cual, procesalmente, se agotó en sede de nulidad, último estadio (salvo que se considere la pertinencia del recurso de queja) que permite pronunciamiento, por ejemplo, respecto de una eventual infracción de ley o de normas constitucionales, ejercicio que, en el ámbito del conocimiento del arbitrio unificador de jurisprudencia, se encuentra vedado, pues, conforme se viene insistiendo, sólo es hábil para revisar y confrontar pronunciamientos dogmáticos, encaminados a

${ }^{81}$ Román Cordero, Cristián, Función pública: entre la laboralización y la deslaboralización, en Revista de Derecho Administrativo Económico 29, p. I7I.

${ }_{82}$ Varas Marchant, Karla, Tutela de derechos fundamentales de los trabajadores públicos: la última palabra la tendrá la Corte Suprema, en Revista Laboral Chilena 283 (enero de 2020). 
reparar una eventual dispersión jurisprudencial» (considerando vigésimo primero). ${ }^{83}$

Ahora bien, si nos imaginamos que la inaplicabilidad se hubiera deducido en otro estadio procesal (previo a la dictación de la sentencia definitiva o antes de la dictación de la sentencia de nulidad), ¿qué efectos habría causa un fallo de inaplicabilidad favorable?

Al respecto, lo primero que debemos decir, tal como también lo afirma la Corte Suprema en la sentencia de unificación que estamos comentando, es que la declaración de inaplicabilidad en caso alguno dispensa al juez del fondo de resolver el conflicto que fue sometido a su conocimiento. En virtud del deber de inexcusabilidad que la Constitución Política impone a los jueces, se debe resolver el caso concreto, ahora, sin hacer uso de las normas legales que han sido declaradas inconstitucionales, claro está. Pero en la resolución del caso concreto, el juez podrá invocar otras normas jurídicas, principios generales del derecho y particulares del derecho del trabajo, tratados internacionales suscritos por Chile y arribar a la misma solución que por medio de la acción de inaplicabilidad se pretendía evitar. $Y$ es que, como se señala en el voto de prevención del ministro Ricardo Blanco, el TC no puede invadir el ámbito propio de la justicia ordinaria. Su labor está encaminada a impedir la aplicación de preceptos legales que, aplicados al caso concreto, resultan contrarios a la Constitución. En caso alguno la competencia del TC puede extenderse «al contenido que debe integrar la resolución de la controversia particular», ni mucho menos a determinar cuál o cuáles serían las normas legales que deben aplicarse en reemplazo de aquellas que han sido excluidas.

La resolución del fondo de la controversia, no obstante la intervención del TC, sigue siendo del tribunal del fondo, el que gozará de plena autonomía para dirimir el conflicto, sobre todo cuando el TC, a través de su intervención, desborda sus competencias, resolviendo una cuestión que es de mera legalidad. ${ }^{84}$

${ }^{83}$ A diferencia de lo que sostiene la Corte Suprema, Román Cordero estima que al declararse inaplicables los preceptos legales que sustentan la tesis de competencia de los tribunales del trabajo para conocer acciones de tutela de derechos fundamentales, si bien se produce como efecto su exclusión, esto obligaría a la Corte Suprema, en virtud del principio de inexcusabilidad, a fallar a favor de la tesis negativa — la de la incompetencia-, lo que conlleva, a su juicio, a que sea el propio Tribunal Constitucional el que indirectamente resuelva el recurso de unificación, lo cual es de suma gravedad ya que se invaden las competencias de la Corte Suprema. Román Cordero, Cristian, cit. (n. 8I), pp. I73-I74.

${ }^{84}$ Como ocurrió respecto de la solicitud de inaplicabilidad del artículo I, inciso tercero, en relación con el artículo 7 del Código del Trabajo, realizada por el Juez del Trabajo, Ricardo Araya (rol 5808-I8-INA), el TC debió haber resuelto que en la especie no existía 
Reiteramos entonces, que posintervención del TC, la última palabra la tendrá el juez que conoce de la causa.

\section{A MODO DE CONCLUSIÓN}

Existen importantes argumentos para sostener que la mera circunstancia de estar sujeto a un estatuto especial de carácter público no obsta a la aplicación de la acción de tutela de derechos fundamentales regulada en el Código del Trabajo. En primer lugar, por una cuestión básica y evidente: los trabajadores del Estado, en su calidad de ciudadanos, son titulares de derechos fundamentales, los que son plenamente exigibles en su relación con el Estadoempleador. ${ }^{85}$ Desconocer aquello equivaldría a negarles su condición de personas y ciudadanos, lo que carecería de razonabilidad y sustento jurídico en un Estado democrático de derechos.

Ahora, no basta con el mero reconocimiento de la vigencia de los derechos fundamentales al interior de la relación laboral pública para entender que su ejercicio está plenamente garantizado, sino que es necesario que existan herramientas judiciales adecuadas y precisas que permitan dejar indemnes estos derechos ante eventuales lesiones del Estado-empleador.

un conflicto de constitucionalidad sino una controversia jurídica sobre la aplicación supletoria del Código del Trabajo a funcionarios públicos regidos por estatutos especiales. Ahora, de entenderse que su competencia se extiende a cuestiones de mera legalidad, como indica Román Cordero, el TC debió haberse «autolimitado en el ejercicio de su atribución para resolver sobre la inaplicabilidad de preceptos legales (judicial self restraint), entre otras razones, por deferencia al juzgador", como lo había hecho previamente en una inaplicabilidad idéntica a la de la sentencia en comento, resolviendo por unanimidad su inadmisibilidad, pues "no somete a esta magistratura un verdadero conflicto constitucional [...], sino que plantea un asunto de mera legalidad en relación con el estatuto legal laboral aplicable a la resolución de la gestión pendiente, asunto de resorte exclusivo de los jueces de fondo" (Sentencia del TC en causa rol 3.230-20i6). Román Cordero, Cristian, cit. (n. 8I), pp. I73-I74.

${ }^{85}$ Ello se desprende del propio texto constitucional, el que en su artículo I inciso primero señala que "las personas nacen libres e iguales en dignidad y derechos» y en su artículo 5 inciso segundo dispone que «el ejercicio de la soberanía reconoce como limitación el respeto de los derechos esenciales que emanan de la naturaleza humana. Es deber de los órganos del Estado respetar y promover tales derechos, garantizados por esta Constitución, asi como por los tratados internacionales ratificados por Chile y que se encuentren vigentes», así como del principio de vinculación directa de la Constitución consagrado en su artículo 6, «los órganos del Estado deben someter su acción a la Constitución y a las normas dictadas conforme a ella, y garantizar el orden institucional de la República. Los preceptos de esta Constitución obligan tanto a los titulares o integrantes de dichos órganos como a toda persona institución o grupo", y finalmente, del listado de derechos fundamentales que la Constitución asegura a todas las personas (artículo ig). 
Ante el escenario de incertidumbre que vivían los empleados públicos en torno a la posibilidad de impetrar una acción de tutela de derechos fundamentales regulada en el Código del Trabajo, la Ley 2I.280, promulgada el 9 de noviembre de 2020, optó por la laboralización, al interpretar el inciso primero del artículo 485 del Código del Trabajo en el sentido que la acción de tutela es aplicable a todos los trabajadores, incluidos los trabajadores del Estado. De esta manera, el legislador confirma la doctrina contenida en el caso Bussenius, relativa a que los funcionarios públicos, no obstante estar sujetos a un estatuto especial, tienen la calidad de trabajadores, y su relación con el Estado es de naturaleza laboral.

Se marca con ello una clara señal hacia la laboralización, al menos en el sentido débil expuesto, ya que se reconoce que, tal como ocurre en la relación de trabajo privada, en el ámbito público hay un trabajador que presta un servicio personal, material o intelectual, para un tercero - el Estado-, quien organiza, dirige y controla ese trabajo, obligándose a pagar por dichos servicios una remuneración determinada. En ambos casos el trabajador se incorpora a una organización de forma continua, con un régimen de jornada uniforme, a fin de desempeñar una determinada función que es controlada y supervisada a través de la línea jerárquica respectiva, y a cambio del cual se recibe una retribución periódica. En definitiva, estamos ante un mismo intercambio de trabajo por remuneración, donde la nota distintiva que justifica la existencia de un mecanismo judicial especial de protección de los derechos fundamentales, cruza a ambas relaciones de trabajo: la desigual distribución del poder. ${ }^{86}$

En suma, el Estado-empleador no está ajeno de realizar actos o conductas que lesionen los derechos fundamentales de sus trabajadores, razón por la cual, la interpretación realizada por el artículo i de la Ley 2I.280 fue la correcta.

Este se trata de un importante avance para la protección de los derechos de los trabajadores públicos, que en el futuro debe ser reforzado por el establecimiento de mecanismos de impugnación general de las causales de cese de la función pública, para de esa manera garantizar de forma

${ }^{86}$ Como indica Sinzheimer, la relación de trabajo es ante todo una relación de poder, poder que detenta el empleador y que ejerce sobre el trabajador no solo en relación con aspectos obligacionales — exigir la prestación debida—, sino que, además, en aspectos jurídico-personales. Esto explica que, en la relación de trabajo, a diferencia de otras formas de prestación de servicios, el empleador tenga un poder de mando sobre el trabajador, y este, la obligación de obedecerlo. Sinzheimer, Hugo, Crisis económica y derecho del trabajo: cinco estudios sobre la problemática humana y conceptual del derecho del trabajo (Madrid, Instituto de Estudios Laborales y de la Seguridad Social, 1984), p. 75-76. 
efectiva la tutela judicial de quienes son despedidos de forma injustificada o indebida.

\section{BibLIOGRAFÍA}

Biblioteca del Congreso Nacional de Chile, Historia de la Ley I8.620 Código del Trabajo, Informe de la Secretaría de Legislación.

Binder Rosas, Jaime, La laboralización de la función pública y la nueva gestión pública, en Boletín Oficial de la Dirección del Trabajo (julio de 2002).

Caldera Delgado, Hugo, Manual de Derecho Administrativo (Santiago, Editorial Jurídica de Chile, 1979).

Cantero Martínez, Josefa, El empleo público: entre el estatuto funcionarial y el contrato laboral (Barcelona, Marcial Pons, 200I).

Díaz, Cecilia, ¿Tutela laboral de funcionarios públicos? (Santiago, Editorial Libromar, 2019).

Gamonal Contreras, Sergio, Ciudadanía en la empresa o los derechos fundamentales inespecificos (Montevideo, Fundación de Cultura Universitaria, 2004).

Gamonal Contreras, Sergio, Lineamientos de Derecho del Trabajo (Santiago, Lexis Nexis, 2006).

Gamonal Contreras, Sergio, Trabajo y derecho (Santiago, Thomson Reuters, 20IO).

IzQuierdo Hernández, Francisco Javier y Molina García, Mónica, $L a$ laboralización de los funcionarios públicos (Valencia, Tirant Lo Blanch, 1996).

Jeze, Gastón, Principios generales del Derecho Administrativo (Buenos Aires, Editorial Depalma, 1948-1950).

Marín Vallejo, Urbano, Estatuto Administrativo: ¿Régimen en retirada en la Administración Pública chilena?, en Pantoja Bauzá, Rolando (coord.), La Administración del Estado de Chile. Decenio 1990-200o (Santiago, Editorial Jurídica Cono Sur, 2000).

Marzi Muñoz, Daniela, Tutela de derechos fundamentales en el sector público y el avance de la realidad, en Revista Laboral Chilena 194.

Parada, Ramón, Derecho Administrativo (Madrid, Editorial Marcial Pons, I998), III.

Parada, Ramón, Derecho Administrativo II. Organización y empleo público (Madrid, Editorial Marcial Pons, 1996).

Peña, Carlos, Sistema juridico y derechos humanos (Santiago, Universidad Diego Portales, 1996). 
Rajevic, Enrique, La crisis de la regulación del empleo público en Chile. Ideas para un nuevo modelo, en Aninat, Isabel y Razmilic, Slaven (eds.), Un Estado para la ciudadanía. Estudios para su modernización (Santiago, Centro de Estudios Públicos, 20I8).

Rajevic, Enrique, La precarización del empleo público en Chile y el mito de la carrera funcionaria, en Quinto Encuentro Anual de la Sociedad Chilena de Políticas Públicas (Santiago, enero de 20I4).

Rajevic, Enrique; Goya, Felipe y Pardo, Carlos, Los puestos directivos en el Estado chileno. Hacia un sistema de gerencia pública (Santiago, Centro de Estudios Públicos, 2002), II.

Román Cordero, Cristián, Función pública: entre la laboralización y la deslaboralización, en Revista de Derecho Administrativo Económico 29.

Sala Franco, Tomás, Incidencia de la legislación laboral en el marco de la función pública (Madrid, Inap, 1989).

SÁnchez Morón, Miguel, Derecho de la función pública ( $5 .^{\text {a }}$ edición, España, Editorial Tecnos, 2008).

Silva Cimma, Enrique, Derecho Administrativo chileno y comparado (Santiago, Editorial Jurídica de Chile, 1993).

Sinzheimer, Hugo, Crisis económica y derecho del trabajo: cinco estudios sobre la problemática humana y conceptual del derecho del trabajo (Madrid, Instituto de Estudios Laborales y de la Seguridad Social, 1984).

Sото KLoss, Eduardo, La idea institucional del Estatuto Administrativo en el Derecho Chileno, en Revista de Derecho Público 25-26 (1979).

Supiot, Alain, Derecho del Trabajo (Buenos Aires, Editorial Heliasta, 2008).

Thayer Arteaga, William, y Novoa Fuenzalida, Patricio, Derecho del Trabajo (Santiago, Editorial Jurídica de Chile, I998), II.

Ugarte, José Luis, Derechos fundamentales en el contrato de trabajo (Santiago, Legal Publishing, 2013).

Ugarte, José Luis, El nuevo derecho del trabajo (Santiago, Lexis Nexis, 2007).

Ugarte, José Luis, Tutela de derechos fundamentales del trabajador (Santiago, Editorial Legal Publishing, 2009).

Valdivia, José Miguel, Manual de Derecho Administrativo (Valencia, Tirant lo Blanch, 20I8).

Varas Marchant, Karla, Tutela de derechos fundamentales de los trabajadores públicos: la última palabra la tendrá la Corte Suprema, en Revista Laboral Chilena 283 (enero de 2020). 


\section{Jurisprudencia judicial}

Corte de Apelaciones de Coyhaique, causa rol i-20io, caratulada «Pinto con Dirección General de Aeronáutica Civil».

Corte de Apelaciones de San Miguel, causa rol 236-20i7, caratulada «Arriaza con Ilustre Municipalidad de San Miguel».

Corte de Apelaciones de Santiago, causa rol iis5-20io, caratulada «Campos con Ministerio de Educación».

Corte de Apelaciones de Santiago, causa rol 850-20io, caratulada «Riquelme con Consejo Nacional de la Cultura y las Artes».

Corte de Apelaciones de Temuco, causa rol I42-20Io, caratulada «Gajardo con Intendencia Regional de la Araucanía».

Corte de Apelaciones de Valparaíso, causa rol 334-20iI, caratulada «Torrealba con Consejo Nacional de la Cultura y las Artes».

Corte de Apelaciones de Valparaíso, causa rol 334-20iI, caratulada «Torrealba con Consejo Nacional de la Cultura y las Artes».

Corte de Apelaciones de Valparaíso, causa rol 350-20il, caratulada "Jeldes con Gobierno Regional de Valparaíso».

Corte Suprema de Chile, causa rol 21.027-20I9, caratulada «Confederación Nacional de Funcionarios con Tribunal Constitucional».

Corte Suprema de Chile, recurso de unificación de jurisprudencia en causa rol I0.972-2013, caratulada «Bussenius con Central Nacional de Abastecimiento».

Corte Suprema de Chile, recurso de unificación de jurisprudencia en causa rol 17.306-2019, caratulada «Signorelli con Fisco de Chile».

Corte Suprema de Chile, recurso de unificación de jurisprudencia en causa rol I8.566-2019, caratulada «Bravo con Policía de Investigaciones de Chile».

Corte Suprema de Chile, recurso de unificación de jurisprudencia en causa rol I8.740-20I8, caratulada «Palma con Hospital Militar».

Corte Suprema de Chile, recurso de unificación de jurisprudencia en causa rol 1972-20II, caratulada «Castillo con Intendencia Regional de la Araucanía».

Corte Suprema de Chile, recurso de unificación de jurisprudencia en causa rol 5967-2013, caratulada «Andrade con Ministerio Público».

Corte Suprema de Chile, recurso de unificación de jurisprudencia en causa rol 938I-20I2, caratulada «Rosas con Servicio de Salud Sur».

Corte Suprema de Chile, recurso de unificación de jurisprudencia en causa rol 94I-20I8, caratulada «Rivas con Corporación Municipal de Valparaíso para el Desarrollo Social».

Juzgado de Letras del Trabajo de Coyhaique, causa RiT T-i-2oi9, 
caratulada «Pinto con Dirección General de Aeronáutica Civil». Juzgado de Letras del Trabajo de San Miguel, causa RIT T-i7-20I7, caratulada «Navarrete con Ilustre Municipalidad de San Miguel».

Juzgado de Letras del Trabajo de Temuco, causa RIT T-i9-20io, caratulada «Gajardo con Intendencia Regional de la Araucanía».

Primer Juzgado de Letras del Trabajo de Santiago, causa RIT T-i320Io, caratulada «Riquelme con Consejo Nacional de la Cultura y las Artes».

Primer Juzgado de Letras del Trabajo de Santiago, causa RIT T-22I20IO, caratulada "Campos con Ministerio de Educación».

Tribunal Constitucional de Chile, causa rol 3853-I7, requerimiento de inaplicabilidad por inconstitucionalidad presentado por la Municipalidad de San Miguel respecto del artículo I, inciso tercero y 485 del Código del Trabajo, en los autos caratulados «Arriaza con Ilustre Municipalidad de San Miguel».

Tribunal Constitucional de Chile, causa rol 5808-20i8, requerimiento de inaplicabilidad por inconstitucionalidad presentado por Ricardo Antonio Araya Pérez, Juez Titular del Segundo Juzgado de Letras del Trabajo de Santiago respecto del artículo I, inciso tercero del Código del Trabajo, en relación con el artículo 7 del mismo cuerpo legal, en los autos RIT O-4I77-20I8, caratulados "Rayo con Fisco de Chile», seguidos ante el Segundo Juzgado de Letras del Trabajo de Santiago.

Tribunal Constitucional de Chile, causa rol 6752-2019, requerimiento de inaplicabilidad por inconstitucionalidad presentado por Ilustre Municipalidad de Arica, respecto de los artículos I, inciso tercero, 485 y 495, todos, del Código del Trabajo, en los autos caratulados «Marambio Núñez con Ilustre Municipalidad de Arica», RIT T-29-20I9, seguidos ante el Juzgado de Letras del Trabajo de Arica.

Tribunal Constitucional de Chile, causa rol 6892-20i9, requerimiento de inaplicabilidad por inconstitucionalidad presentado por Ricardo Antonio Araya Pérez, Juez Titular del Segundo Juzgado de Letras del Trabajo de Santiago respecto del artículo I, inciso tercero del Código del Trabajo, en relación con el artículo 485, del Código del Trabajo, en los autos caratulados "Rosales con Fisco de Chile», RIT T-I48I-20I8, del Segundo Juzgado de Letras del Trabajo de Santiago.

Tribunal Constitucional de Chile, causa rol 7073-20i9, requerimiento de inaplicabilidad por inconstitucionalidad presentado por la Ilustre Municipalidad de Caldera respecto de los artículos I, inciso tercero, y 485, del Código del Trabajo, en los autos caratulados «Torres con Municipalidad de Caldera». 
Tribunal Constitucional de Chile, causa rol 7289-20i9, requerimiento de inaplicabilidad por inconstitucionalidad presentado por la Universidad de Santiago de Chile respecto del artículo I, inciso tercero, del Código del Trabajo, en los autos RIT T-1982-20I8, caratulados "Ochoa con Universidad de Santiago», seguidos ante el Segundo Juzgado de Letras del Trabajo de Santiago.

Tribunal Constitucional de Chile, causa rol 7584-20i9, requerimiento de inaplicabilidad por inconstitucionalidad presentado por el Banco del Estado de Chile respecto de la segunda oración del inciso primero del artículo 4 de la Ley 19.886, y del inciso final del artículo 495 del Código del Trabajo, en los autos caratulados «Cornejo con Banco del Estado de Chile», RIT T-I978-20I8, del Segundo Juzgado de Letras del Trabajo de Santiago.

Tribunal Constitucional de Chile, causa rol 7892-20i9, requerimiento de inaplicabilidad por inconstitucionalidad presentado por Universidad Metropolitana de Ciencias de la Educación respecto de los artículos I, inciso tercero, y 485 del Código del Trabajo, en los autos caratulados «Garay con Universidad Metropolitana de Ciencias de la Educación.

Tribunal Constitucional de Chile, causa rol 8308-2020, requerimiento de inaplicabilidad por inconstitucionalidad presentado por Instituto Nacional de Estadísticas respecto del artículo I, inciso tercero y 485 del Código del Trabajo, en la causa RIT T-I288-20I9, seguida ante el Segundo Juzgado de Letras del Trabajo de Santiago.

\section{Jurisprudencia administrativa}

Contraloría General de la República, dictamen I4.4I2 de 1948. Contraloría General de la República, dictamen 22.766 de 2016. Contraloría General de la República, dictamen I4.498 de 2019.

\section{SOBRE LA AUTORA}

Karla Varas Marchant es abogada de la Universidad de Chile. Doctora en Derecho de la Universidad Diego Portales y la Universidad de Salamanca, España. Profesora asociada de Derecho del Trabajo en la Facultad de Derecho de la Pontificia Universidad Católica de Valparaíso. Su correo electrónico es karla.varas@pucv.cl. 